\title{
Constraint-Induced Movement Therapy in the Adult Rat after Unilateral Corticospinal Tract Injury
}

\author{
Irin C. Maier, ${ }^{1,2}$ Kaspar Baumann, ${ }^{1,2}$ Michaela Thallmair, ${ }^{1,2}$ Oliver Weinmann, ${ }^{1,2}$ Jeannette Scholl, ${ }^{1,2}$ and \\ Martin E. Schwab ${ }^{1,2}$ \\ ${ }^{1}$ Brain Research Institute, University of Zurich, and 2Department of Biology, Swiss Federal Institute of Technology, 8057 Zurich, Switzerland
}

\begin{abstract}
Smaller spinal cord injuries often allow some degree of spontaneous behavioral improvements because of structural rearrangements within different descending fiber tracts or intraspinal circuits. In this study, we investigate whether rehabilitative training of the forelimb (forced limb use) influences behavioral recovery and plastic events after injury to a defined spinal tract, the corticospinal tract (CST). Female adult Lewis rats received a unilateral CST injury at the brainstem level. Use of the contralateral impaired forelimb was either restricted, by a cast, or forced, by casting the unimpaired forelimb immediately after injury for either 1 or 3 weeks. Forced use of the impaired forelimb was followed by full behavioral recovery on the irregular horizontal ladder, whereas animals that could not use their affected side remained impaired. BDA (biotinylated dextran amine) labeling of the intact CST showed lesion-induced growth across the midline where CST collaterals increased their innervation density and extended fibers toward the ventral and the dorsal horn in response to forced limb use. Gene chip analysis of the denervated ventral horn revealed changes in particular for growth factors, adhesion and guidance molecules, as well as components of synapse formation suggesting an important role for these factors in activity-dependent intraspinal reorganization after unilateral CST injury.
\end{abstract}

Key words: corticospinal tract; forced limb use; spinal cord injury; plasticity; rehabilitation; activity

\section{Introduction}

Injury to the spinal cord leads to a disruption of ascending and descending fiber tracts followed by loss of sensation and voluntary movements below the level of the lesion. Whereas large injuries often lead to permanent disabilities, smaller lesions are followed by some degree of spontaneous functional recovery (Blight, 1993; Burns et al., 1997; Little et al., 1999), which can be increased by rehabilitative therapies. The benefits of training on the recovery of sensory and locomotor function after spinal cord injury (SCI) have been demonstrated in animal models (Rossignol et al., 1999; Edgerton et al., 2004) and SCI patients (Barbeau and Rossignol, 1994; Dietz et al., 1998), but the underlying mechanisms are still poorly understood.

Regeneration and adaptive changes in response to injury are limited in the adult mammalian CNS because of intrinsic neuronal mechanisms and environmental factors (Schwab, 2002; Yiu and $\mathrm{He}, 2006)$. Nevertheless, spontaneous reorganization has been reported on different levels and within different descending fiber tracts (Raineteau and Schwab, 2001; Bareyre et al., 2004)

Received April 18, 2008; revised June 26, 2008; accepted Aug. 6, 2008.

This work was supported by Swiss National Science Foundation Grant 31-63633.00, National Center of Competence in Research "Neural Plasticity and Repair" of the Swiss National Science Foundation, and Spinal Cord Consortium of The Christopher and Dana Reeve Foundation (Springfield, NJ). We thank Laura Montani and the Functional Genomics Center Zurich for assistance with the gene chips, MichelleStarkey for critical review of this manuscript, and Roman Willi for assistance with the statistics.

Correspondence should be addressed to Irin C. Maier, Brain Research Institute, Winterthurerstrasse 190, 8057 Zurich, Switzerland. E-mail: imaier@hifo.uzh.ch.

D0I:10.1523/JNEUROSCI.1697-08.2008

Copyright $\odot 2008$ Society for Neuroscience $\quad$ 0270-6474/08/289386-18\$15.00/0 and might contribute to spontaneous functional improvements (Dobkin, 2000).

The corticospinal tract (CST), as one of the most important descending motor pathways for skilled movements in all mammalian species (Nudo and Masterton, 1988, 1990), has been a frequent target to investigate injury-induced plasticity within the adult CNS (Weidner et al., 2001; Bareyre et al., 2004). Within recent years, there have been many attempts to increase the plastic potential of the injured CST. Neutralization of growth inhibitors such as Nogo-A or the Nogo-A receptor NgR (Thallmair et al., 1998; Schwab, 2004; Cafferty and Strittmatter, 2006) as well as the expression of neurotrophic factors (Zhou and Shine, 2003; Zhou et al., 2003) after unilateral CST injury were followed by increased growth of collaterals from the intact tract across the midline. Additionally, stimulation of the intact CST promoted outgrowth of ventral fibers into the denervated gray matter (Brus-Ramer et al., 2007).

Research on plasticity and neurorehabilitation after SCI has mostly focused on the recovery of hindlimb/leg function. Assessing the effect of training on forelimb/hand function and the underlying structural and molecular mechanisms has proven to be much more difficult and complex. In one study, Girgis et al. (2007) showed that training of a reaching task was paralleled by increased sprouting of lesioned CST fibers above the injury followed by behavioral recovery of grasping.

In this study, we investigate the effect of forced limb use after unilateral CST injury on behavioral recovery, compensatory growth, arborization, and synapse formation of the uninjured CST. We also use a gene chip approach to define some of the key factors within the denervated spinal cord that could account for 

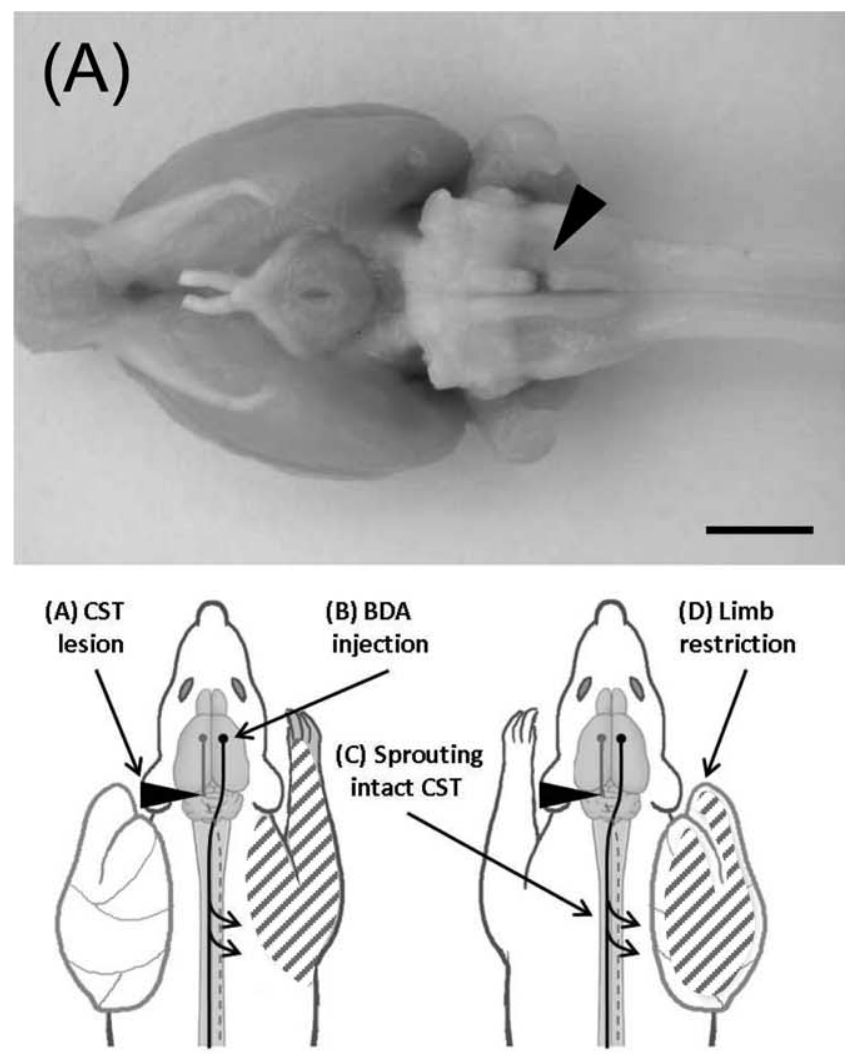

(E) Forced use of CST deafferented limb

(F) Forced non-use of CST deafferented limb

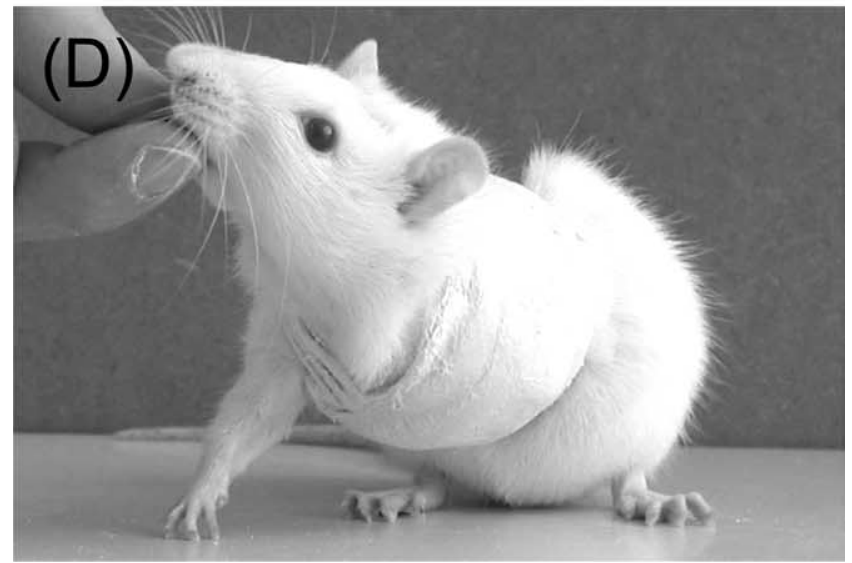

Figure 1. Pyramidotomy, cast, and experimental setup. The sequence of experimental steps is shown in the central panel. $A$, Animals received a unilateral lesion of the CST at the level of the medulla oblongata. Arrowhead, Top, Ventral aspect of brain with lesion. $\boldsymbol{B}$, The neuronal tracer BDA was injected into the opposite sensorimotor cortex. $C$, Midline-crossing fibers of the intact CST were counted 1 and 3 weeks after injury at the cervical level. $\boldsymbol{D}$, A plaster of paris cast immobilized the limb ipsilateral or contralateral to the lesion forcing the animal to completely rely on either the impaired $(\boldsymbol{E})$ or unimpaired $(\boldsymbol{F})$ forelimb for either 1 or 3 weeks. Bottom, Rat with restricted limb. Scale bar, $5 \mathrm{~mm}$.

structural and cellular rearrangements in response to injury and forced limb use.

\section{Materials and Methods}

\section{Experimental setup}

Adult female Lewis rats (180-200 g) were obtained from a specific pathogen-free breeding colony ( $\mathrm{R}$. Janvier) and kept as groups of four animals in standardized cages (type 4 Macrolon) at a $12 \mathrm{~h}$ light/dark cycle on a standard regimen with food and water ad libitum. After biotinylated dextran amine (BDA) tracer injections into the contralesional forelimb
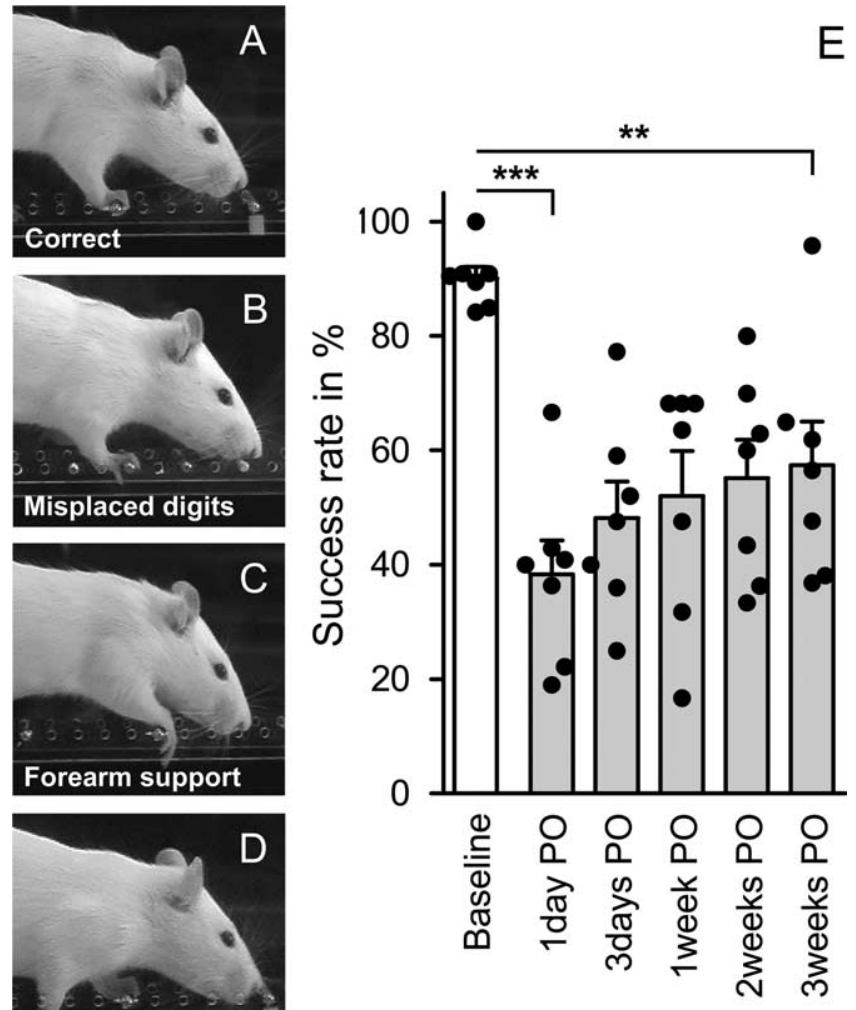

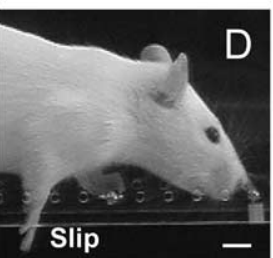

Figure 2. Effect of CST lesion and spontaneous recovery of skilled forelimb function on the irregular horizontal ladder. $\boldsymbol{A}$, Uninjured animals precisely grasp each rung with all four digits placed in front of the metal bar. $\boldsymbol{B}-\boldsymbol{D}$, After unilateral CST injury, the following mistakes could be observed: animals misplaced one or more digits on the backside of the rung $(\boldsymbol{B})$; failed to place the palm of their paw directly onto the rung $(\boldsymbol{C})$; slipped off the rung or placed their paw between single rungs $(\boldsymbol{D})$. $\boldsymbol{E}$, Success rate of each animal was expressed as percentage of correct steps of all steps taken by the impaired forelimb. Pyramidotomy led to a significantly lower success rate of the impaired forelimb on the horizontal ladder (ANOVA, $F=113.16, p \leq 0.001$; $n=7$ ). Some spontaneous improvement occurred in all animals within the next 3 weeks, but success rate remained low (Bonferroni's post hoc, $p \leq 0.01$ ). P0, Postoperative. Data are presented as means $\pm \mathrm{SEM}$; single data points (black circles) represent single animals. ${ }^{* *} p \leq 0.01$; ***p $\leq$ 0.001. Scale bar, $1 \mathrm{~cm}$.

motor cortex (described below), rats were divided into the following experimental groups: unlesioned animals (intact), animals receiving a sham operation (sham), and animals with unilateral CST injury (Рyx) at the brainstem level. Sham-operated as well as injured animals were further subdivided: One group of animals returned to their home cage in which they were able to freely move without any restrictions (free use). In all other animals, a plaster of paris cast immobilized either the limb ipsilateral or contralateral to the lesion, forcing the animals to completely rely on their impaired (forced use) or their unimpaired (forced nonuse) forelimb for either 1 or 3 weeks (Fig. 1). Additional groups of animals were operated, casted, and used for gene chip analysis. All experiments were performed according to the guidelines of the Veterinary Office of the Canton of Zurich, Switzerland.

\section{$B D A$ tracing}

All surgical procedures were performed under aseptic conditions. One week before injury, animals were deeply anesthetized with a subcutaneous injection of Hypnorm $(0.3 \mathrm{mg} / \mathrm{kg}$ body weight; VetaPharma $)$ and Dormicum $(0.6 \mathrm{mg} / \mathrm{kg}$ body weight; Roche Pharmaceuticals). For anterograde tracing of the unlesioned CST, the caudal forelimb area of the contralesional sensorimotor cortex was exposed (Neafsey et al., 1986). A $10 \%$ solution of BDA (10,000 molecular weight; Invitrogen) in $0.01 \mathrm{M}$ PBS (0.1 PB) was pressure injected stereotactically into the right motor cortex (coordinates: $1.5 \mathrm{~mm}$ anterior to bregma, $2 \mathrm{~mm}$ lateral to bregma, 
$1.5 \mathrm{~mm}$ depth) using a $5 \mu \mathrm{l}$ Hamilton syringe driven by an electric pump with a flow rate of 5 $\mathrm{nl} / \mathrm{s}$. A total volume of $3 \mu \mathrm{l}$ was injected at five injection sites, separated by $500 \mu \mathrm{m}$. The syringe remained in place for $3 \mathrm{~min}$ after completion of each injection.

\section{Surgery}

One week after BDA injection, all animals were anesthetized as described above. Unilateral pyramidal tract lesions were made according to the method described previously (Thallmair et al., 1998; Z'Graggen et al., 1998) (Fig. 1 A). Using an anterior approach, the ventral midline was transected, trachea and esophagus were carefully displaced to the left, and the surface of the occipital bone was exposed by a deep blunt dissection. A small hole was drilled into the bone, which revealed the medullary pyramids. The dura was removed and a fine tungsten needle inserted into a depth of $\sim 1 \mathrm{~mm}$ below the ventral brainstem surface just lateral to the basilar artery. The needle was laterally displaced and gently lifted, transecting the left CST just rostral to its decussation. In sham-operated animals, the dura was removed but the CST was left undamaged. Finally, esophagus and trachea were replaced, and the muscles and skin were closed by suture. Completeness of the injury was confirmed by histology approach in all animals and in a sample of animals by anterograde tracing of both sides of the CST with BDA. Animals with incomplete lesions were excluded from additional studies.

\section{Forelimb immobilization}

Immediately after pyramidotomy surgery while animals were still anesthetized, one forelimb was restricted as previously described (Jones and Schallert, 1994). Animals were randomly assigned to two different groups in which either their impaired or their unimpaired limb was immobilized by a plaster of paris cast that resembled a one-holed vest around their upper torso and one limb (Fig. 1C). Animals were forced to completely rely on either their impaired (forced use) or their unimpaired forelimb (forced nonuse) for either 1 or 3 weeks starting immediately after injury. To facilitate grooming and body hygiene, all rats were randomly assigned to groups of a minimum of four animals per cage. Correct position of the cast was checked on each animal twice per day. Occasionally, animals were able to remove their cast but were recasted immediately under light isoflurane anesthesia. All casts were removed either 1 or 3 weeks after injury, and animals were able to recover for $48 \mathrm{~h}$ before their performance was tested on the horizontal ladder test.

\section{Horizontal ladder test}

Two weeks before baseline "recordings," animals were accustomed to the testing apparatus every other day until each animal voluntarily crossed the ladder in a slow consistent speed. The ladder was $1 \mathrm{~m}$ long and elevated $1 \mathrm{~m}$ over ground. To prevent habituation to a specific bar distance, bars were irregularly spaced $(1-6 \mathrm{~cm})$ and each animal had to cross the ladder in both
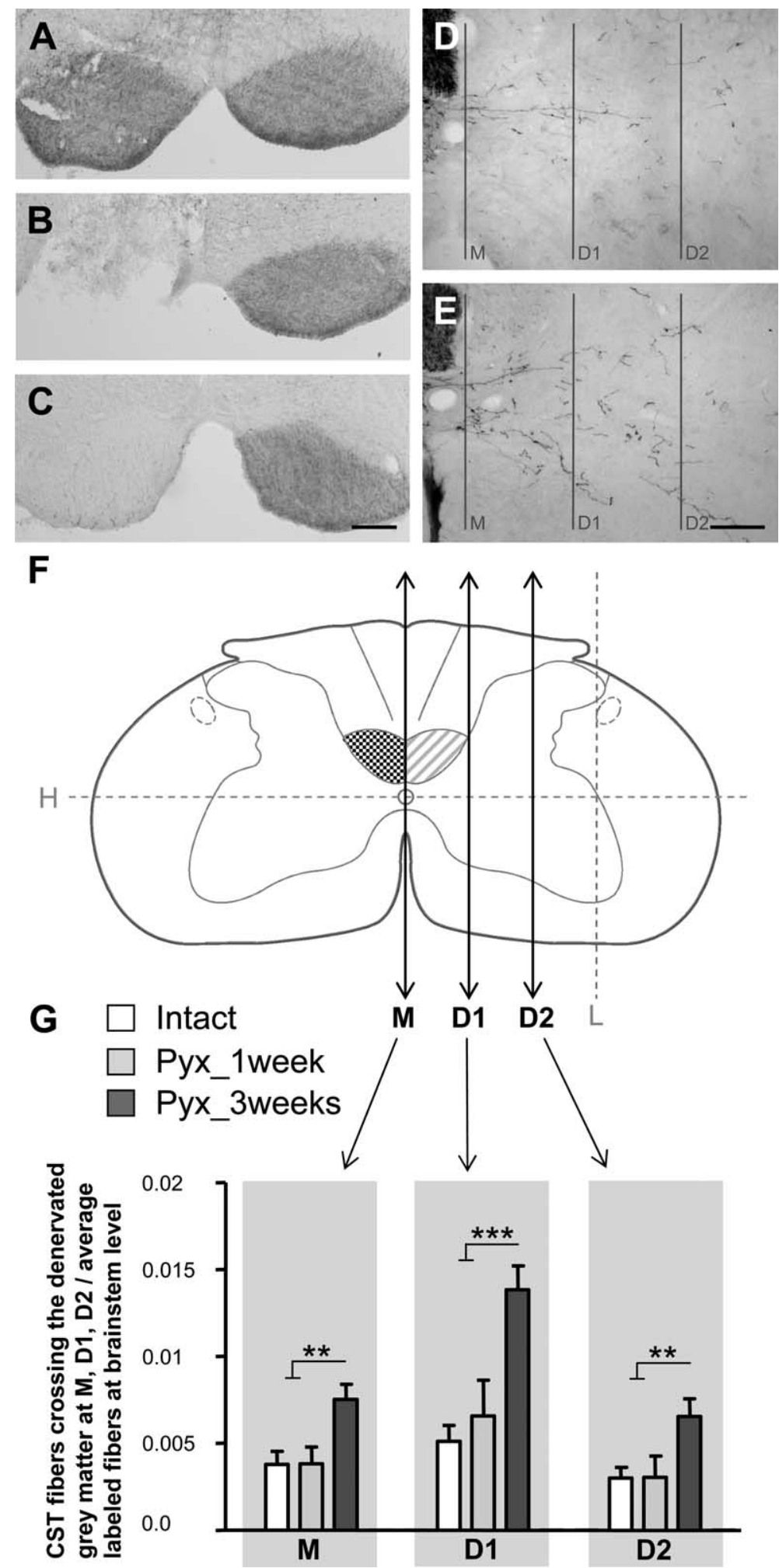

Figure 3. Lesion-induced growth of the intact CST across the midline and into the denervated gray matter. $A$, Bilateral BDA pressure injections into the forelimb motor cortex label both CST tracts. $B$, $C$, Complete interruption of one CST at the level of the caudal medulla oblongata $(\boldsymbol{B})$ leads to interruption of BDA transport caudal to the injury $(\boldsymbol{C}) . \boldsymbol{D}, \boldsymbol{E}$, Representative pictures of BDA-labeled CST fibers in the contralateral gray matter of intact $(\boldsymbol{D})$ or injured $(\boldsymbol{E})$ animals 3 weeks after injury. $\boldsymbol{F}$, Fibers of the intact CST were quantified by counting all intersections with lines $M, D 1$, and D2. M was placed vertically through the midline. D1 and $D 2$ were drawn parallel to $M$ at one-third and two-thirds of the distance between the central canal and the lateral gray matter border. $G$, In intact rats (intact; $n=7$ ), only few CST axons crossed the midline and branching was minimal. One week after injury (Pyx_1 week; $n=5$ ), there was no change in the amount of labeled CST fibers. After 3 weeks (Pyx_3 weeks; $n=7$ ), the number of CST collaterals projecting over the midline and branching within the denervated gray matter significantly increased (ANOVA, Bonferroni's post hoc: $\mathrm{M}, p \leq 0.01 ; \mathrm{D} 1, p \leq 0.001 ; \mathrm{D} 2, p \leq 0.01$ ). Data are presented as means \pm SEM. ${ }^{* *} p \leq 0.01 ;{ }^{* * *} p \leq$ 0.001. Scale bars: $A-C, 200 \mu \mathrm{m} ; \boldsymbol{D}, \boldsymbol{E}, 100 \mu \mathrm{m}$. 

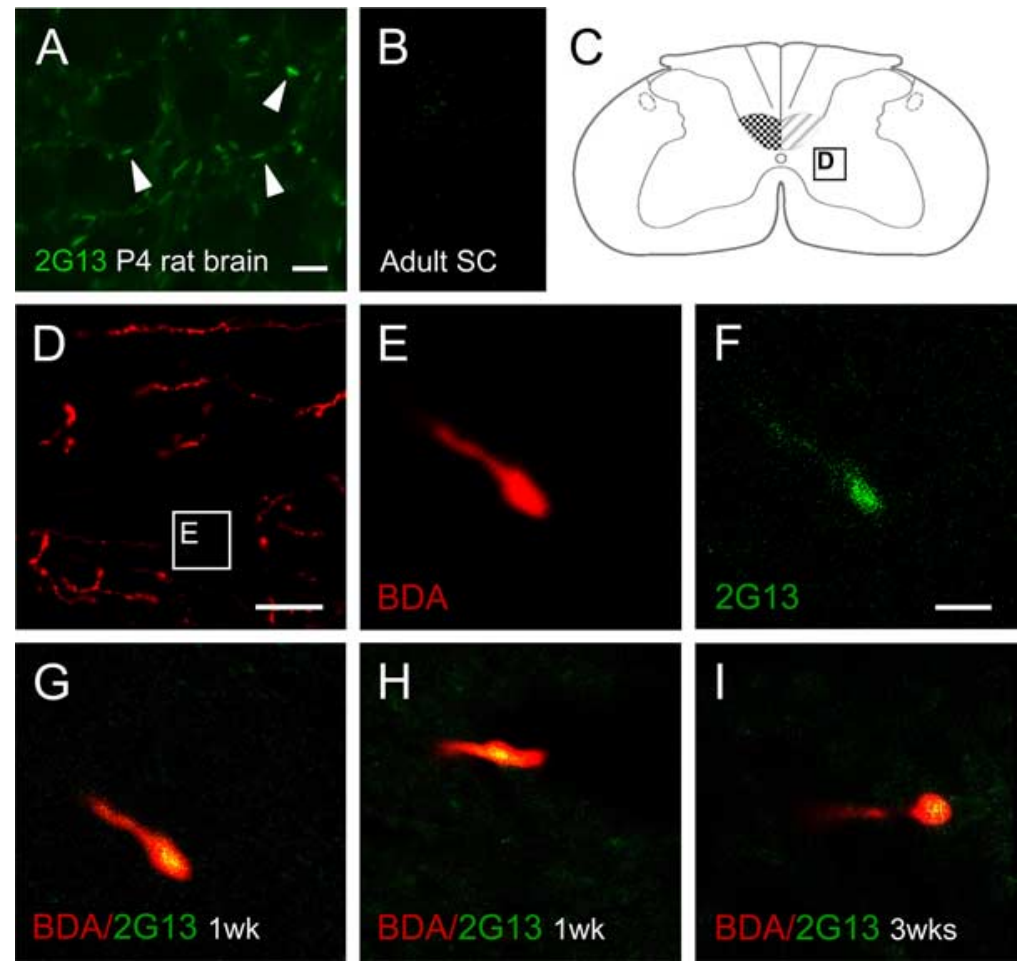

Figure 4. Growth of CST fibers within lamina VII of the denervated cervical spinal cord. $A, 2$ G13 antibodies (green) specifically label axonal growth cones as demonstrated in the developing rat neocortex (P4). Arrowheads, 2G13-positive growth cones. $\boldsymbol{B}$ Constitutive expression of $2 \mathrm{G} 13$ was absent in the adult spinal cord (intermediate zone) $C$, Schematic spinal cord cross section with sampling area for $\boldsymbol{D}$. $\boldsymbol{D}$, Fibers of the intact CST (labeled with BDA; red) within the denervated gray matter. $\boldsymbol{E}$, Terminal end of BDA labeled CST fiber. $\boldsymbol{F}, 2$ 2 13-positive growth cone in the denervated gray matter of fiber shown in $\boldsymbol{D}$. G-I, Confocal analysis reveals colocalization of BDA (red) and 2G13 (green) at the terminal end of CST fibers 1 week $(\boldsymbol{G}, \boldsymbol{H})$ and 3 weeks $(\boldsymbol{I})$ after injury demonstrating growth of CST fibers within the denervated gray matter. Scale bars: $\boldsymbol{A}, \boldsymbol{B}, 10 \mu \mathrm{m} ; \boldsymbol{D}, 50 \mu \mathrm{m} ; \boldsymbol{E}-\boldsymbol{I}, 2 \mu \mathrm{m}$.

directions. For behavioral testing, three runs over a defined $60 \mathrm{~cm}$ stretch were filmed and evaluated using frame-by-frame video analysis (Virtualdub; www.virtualdub.org). In unconstrained animals (free use), locomotor performance and spontaneous recovery of the impaired forelimb was evaluated immediately after injury and then once per week. These testing sessions were few and short to prevent additional forelimb training effects. Casted animals were tested only once, $48 \mathrm{~h}$ after cast removal.

We judged forepaw placement as normal when all four digits were placed in front of the rung (see Fig. $2 \mathrm{~A}$ ). After injury, the following mistakes were observed and counted as errors: (1) animals misplaced one or more digits on the backside of the rung, (2) rats failed to place the palm of their paw directly onto the rung but used their wrist or forearm for support, (3) animals misplaced their paw on the rung and slipped off the rung or completely missed single rungs (see Fig. $2 B-D$ ). Success rate was expressed as percentage of correct steps of all steps taken by the impaired limb.

\section{Immunohistochemistry and histological analysis}

Tissue preparation. After the completion of behavioral testing, all animals were deeply anesthetized with pentobarbital $(450 \mathrm{mg} / \mathrm{kg}$ body weight, i.p.; Abbott Laboratories), perfused transcardially with $100 \mathrm{ml}$ of Ringer's solution [containing 100,000 IU/L heparin, Liquemin (Roche), and $0.25 \% \mathrm{NaNO}_{2}$ ] followed by $200 \mathrm{ml}$ of $4 \%$ phosphate-buffered paraformaldehyde, $\mathrm{pH} 7.4$ containing 5\% sucrose. Spinal cords and brains were dissected and postfixed in the same fixative overnight at $4^{\circ} \mathrm{C}$ before they were cryoprotected in phosphate-buffered $30 \%$ sucrose for an additional $5 \mathrm{~d}$.

Diaminobenzidine staining (BDA). The caudal parts of the cervical enlargement (C6-C8) and the brainstems were embedded in a gelatinchicken albumin solution polymerized with $25 \%$ glutaraldehyde and cut in $50-\mu \mathrm{m}$-thick sections on a cutting vibratome as previously described (Z'Graggen et al., 1998). Sections were processed using the nickel- enhanced diaminobenzidine (DAB) protocol according to the semi-free-floating technique of Herzog and Brösamle (1997). Briefly, sections were rinsed three times for $30 \mathrm{~min}$ each time in TBS-TX ( 50 mm Tris, $0.9 \% \mathrm{NaCl}, 0.5 \%$ Triton X-100, pH 8.0) and incubated overnight with an avidin-biotin-peroxidase complex (Vectastain ABC Elite kit; Vector Laboratories; 1:100 in TBS-X) at $4^{\circ} \mathrm{C}$. After three $30 \mathrm{~min}$ washings in TBS-TX, sections were rinsed with $50 \mathrm{~mm}$ Tris- $\mathrm{HCl}, \mathrm{pH} 8.0$, and preincubated with $0.4 \%$ ammonium nickel sulfate (SigmaAldrich) followed by a second preincubation in ammonium nickel sulfate and $0.015 \%$ DAB (Sigma-Aldrich). The tissue was reacted in $0.4 \%$ ammonium nickel sulfate, $0.015 \%$ DAB, and $0.004 \% \mathrm{H}_{2} \mathrm{O}_{2}$ in $50 \mathrm{~mm}$ Tris buffer, $\mathrm{pH}$ 8.0. After 5-10 min, the reaction was stopped with $50 \mathrm{~mm}$ Tris- $\mathrm{HCl}$, sections were rinsed three times for $10 \mathrm{~min}$ each time in $50 \mathrm{~mm}$ Tris- $\mathrm{HCl}$, air-dried overnight, and coverslipped with Eukitt (Kindler).

Immunofluorescence staining (2G13, vGlut1, $B D A)$. The rostral part of the cervical enlargements (C2-C5) as well as one postnatal rat brain [postnatal day 4 (P4)] were embedded in Tissue Tek OCT (Kindler) and frozen in isopentane (Sigma-Aldrich) at exactly $-40^{\circ} \mathrm{C}$. Forty-micrometer-thick sections were cut on a cryostat and transferred into ice-cold PBS. Sections were transferred into postfixation $(4 \%$ paraformaldehyde, $0.1 \%$ glutaraldehyde, $0.1 \%$ saturated picric acid in PB buffer) for $10 \mathrm{~min}$, endogenous peroxidase activity was quenched with ethanol peroxide ( $50 \%$ ethanol plus $0.3 \%$ hydrogen peroxide in $\mathrm{ddH}_{2} \mathrm{O}$ ) followed by 50 $\mathrm{mm}$ glycine (in PBS; $10 \mathrm{~min}$ ) to reduce autofluorescence. After microwave irradiation $(600 \mathrm{~W} ; 30 \mathrm{~s})$ in $0.1 \mathrm{~m}$ Tris buffer, slides were blocked in TNB $(0.1 \%$ casein, $0.25 \%$ bovine serum albumin, $25 \%$ Top block, $0.15 \mathrm{M} \mathrm{NaCl}$, $0.05 \%$ Tween in $0.1 \mathrm{M}$ Tris buffer) for $1 \mathrm{~h}$.

Sections were incubated overnight at $4^{\circ} \mathrm{C}$ with primary antibodies against vesicular glutamate transporter 1 (vGlut1) (1:1000; rabbit; Synaptic Systems) or 2G13 (1:40; mouse; Acris). After washing, they were incubated with high-affinity-purified goat anti-rabbit (1:200) and antimouse (1:100) secondary antibodies (Jackson ImmunoResearch) coupled to CY2 or FITC, respectively. After washing in PBS, sections were blocked in TNB for $30 \mathrm{~min}$ and incubated with an avidin-biotin-peroxidase complex (ABC kit).

Conventional protocols for immunofluorescence failed to detect fine CST collaterals in the cervical gray matter. We therefore developed an improved protocol for the detection of CST collaterals using tyramide signal amplification first described by Adams (1992), and further established by Müllner et al. (2008). Slides were transferred into a self-made tyramide amplification buffer $\left(0.02 \% \mathrm{H}_{2} \mathrm{O}_{2}, 1 \%\right.$ biotinylated tyramide, $0.05 \%$ Tween in PBS) for 5 min. Another blocking step in TNB was followed by $30 \mathrm{~min}$ incubation with Cy3-conjugated streptavidin (1:4000 for double labeling with vGlut1; 1:500 for double labeling with 2G13; Jackson ImmunoResearch). Finally, sections were washed, mounted on glass slides, dried overnight, and coverslipped with Mowiol (Calbiochem).

Pictures of vGlut1 or 2 G13 colocalization with BDA-positive fibers within the denervated ventral gray matter (Rexed's lamina VII) were taken with a confocal microscope (Leica TCS SP2; Leica confocal software, version 2.61)

Quantification of midline-crossing CST fibers. Growth and sprouting in response to injury was evaluated in 40 adjacent cross sections at the caudal cervical enlargement (C6-C8), where motoneuron-columns innervating muscles specifically required for skilled forelimb movements 
are located (McKenna et al., 2000). Midlinecrossing fibers were counted at a final magnification of $400 \times$ in the dorsal and ventral comissure at the central canal (see Fig. 3F, level M), and branching of these fibers was evaluated at two defined regions within the gray matter (see Fig. 3F, levels D1 and D2).

Four vertical $(\mathrm{M}, \mathrm{D} 1, \mathrm{D} 2, \mathrm{~L})$ and one horizontal line $(\mathrm{H})$ were superimposed on each spinal cord section (Neurolucida 7.0; MicroBrightField) as reference points for crossing axons. The first vertical line $\mathrm{M}$ was drawn through the central canal; $\mathrm{H}$ was also drawn through the central canal, perpendicular to $\mathrm{M}$. $\mathrm{L}$ was drawn parallel to $\mathrm{M}$ and crossed $\mathrm{H}$ at the lateral rim of the gray matter. D1 and D2 were drawn parallel to $\mathrm{M}$ at one-third and two-thirds of the distance between $\mathrm{M}$ and $\mathrm{L}$ (see Fig. $3 F$ ). Collateral CST fibers in the gray matter have an irregular course, passing in and out of the plane of the section. To prevent multiple counting of single collaterals, only fibers that crossed $\mathrm{M}$, $\mathrm{D} 1$, or D2 were counted on each section.

To correct for variations in BDA uptake by CST neurons in the sensorimotor cortex, we normalized the quantitative data by counting BDA-labeled axons in the main pyramidal tract in three rectangular areas $\left(150 \mu \mathrm{m}^{2}\right)$ per slide on four adjacent sections at the level of the brainstem (facial nerve). Results are expressed as mean number of fibers at the cervical level crossing $\mathrm{M}, \mathrm{D} 1$, and $\mathrm{D} 2$ divided by the mean of counted fibers at the brainstem level for each animal.

Camera lucida reconstructions of three representative consecutive cross sections of the cervical spinal cord (C6) were performed for three groups (intact, lesioned_3 weeks_forced nonuse/forced use) to visualize the extent and specificity of CST fiber growth in response to injury and forced limb use.

Quantification of BDA-positive synaptic boutons. In each animal, BDA-positive boutons along the length and at the tip of midlinecrossing fibers were counted at a defined area $\left(400 \mu \mathrm{m}^{2}\right)$ on six sections within the denervated gray matter (intermediate zone, Rexed's lamina VII, C6) at a $400 \times$ magnification. The number of boutons was normalized for tracer efficacy as described above.

Quantification of vGlut1 immunoreactivity. Pictures of the contralesional (denervated) as well as the ipsilesional (intact) ventral gray matter (intermediate zone, Rexed's lamina VII, C5) were taken at a $400 \times$ magnification with a confocal microscope on five sections per animal, and vGlut1-positive varicosities were counted on each photograph within a randomly chosen area $\left(400 \mu \mathrm{m}^{2}\right)$. vGlut 1 immunoreactivity was expressed as percentage of vGlut1-positive varicosities within the denervated side compared with the contralateral intact ventral gray matter.

\section{Gene chip analysis}

For the gene chip analysis, one group of rats received a unilateral pyramidotomy and the other group a sham surgery as described above. Both groups were further subdivided into animals that were forced to rely either on their ipsilesional or their contralesional forelimb for 1 week as described above (total: four groups; $n=4$ ). One week after injury, rats were decapitated, and the spinal cords were dissected on a cold plate and frozen in liquid nitrogen. Cervical enlargements were mounted on a cutting microtome, covered with dry
B
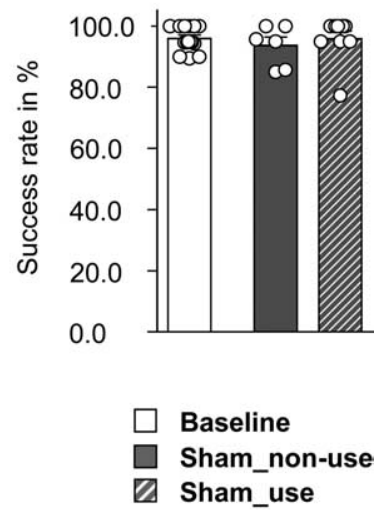

$\mathrm{D}$

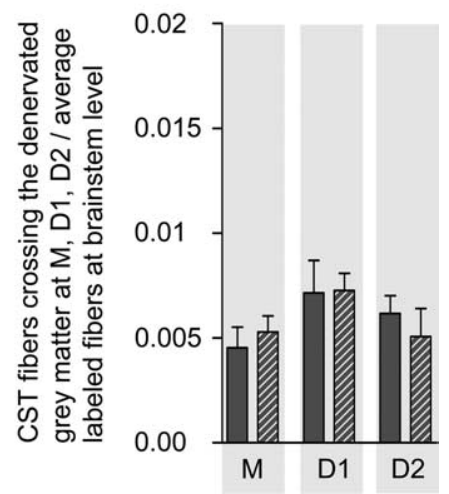

Figure 5. Effect of forced limb use on the recovery of skilled forelimb function and growth of the intact CST into the denervated gray matter. $\boldsymbol{A}$, After lesion, animals were forced to completely rely on their unimpaired or their impaired limb for either 1 or 3 weeks. One week after injury, forced nonuse (Pyx_1 week_nonuse; $n=7$ ) led to a significantly lower success rate on the

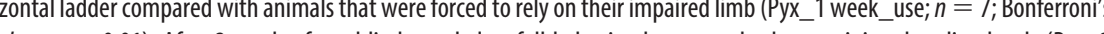
weeks_use; $n=8$ ); animals that could not use their impaired side stayed significantly impaired (Pyx_3 weeks_nonuse; $n=8$; $p \leq 0.001)$. $B$, Forced nonuse or forced use alone did not influence locomotor performance in sham-operated animals (sham_nonuse, $n=6$; sham_use, $n=9$ ). C, Growth and arborization of CST fibers was analyzed by counting all intersections to significant growth of CST fibers across the midline in both groups $\left(\mathrm{M}_{1} p \leq 0.01\right)$. Forced limb use further increased CST

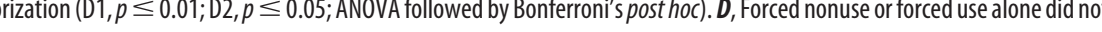
influence growth and arborization of CST fibers in the contralateral, manipulated gray matter (sham_nonuse, $n=6$; sham_use, $n=9$; ANOVA, $p<0.05)$. Data are presented as mean \pm SEM. ${ }^{*} p \leq 0.05 ;{ }^{* *} p \leq 0.01 ;{ }^{* * *} p \leq 0.001$.

ice, and cut into sections of $250 \mu \mathrm{m}$. In each section, the ventral horn of the denervated side was extracted by punch dissections with a blunt syringe (diameter, $1.2 \mathrm{~mm}$ ) (see Fig. $9 A, B$ ). The tissue was immediately transferred into RNA-later (Roche Diagnostics) and subsequently used for total RNA extraction (RNeasy Lipid Tissue kit; QIAGEN). Total RNA was quantified by NanoDrop (ND-100; NanoDrop Technologies), and quality was assessed using a bioanalyzer (2100 Bioanalyzer; Agilent Technologies). For probe preparation, procedures described in the Affymetrix GeneChip Expression Analysis Manual (Affymetrix) were followed. Biotinylated cRNA was hybridized onto Affymetrix Genome arrays (Rat Expression Array 230 2.0; Affymetrix), which represent $>45,000$ probe sets in the Affymetrix Fluidics Station 450, and chips were scanned with the Affymetrix Scanner 3000. Each chip was used for hybridization with cRNA isolated from one spinal cord sample from a single animal. Thus, there was a total number of 16 samples. Results were subsequently analyzed using the Affymetrix Microarray Suite 5, followed by the Genespring 7.2 (Silicon Genetics). We applied a present call filter (at least in three of four animals), fold change thresholds (1.2/0.8), and ANOVA (with 

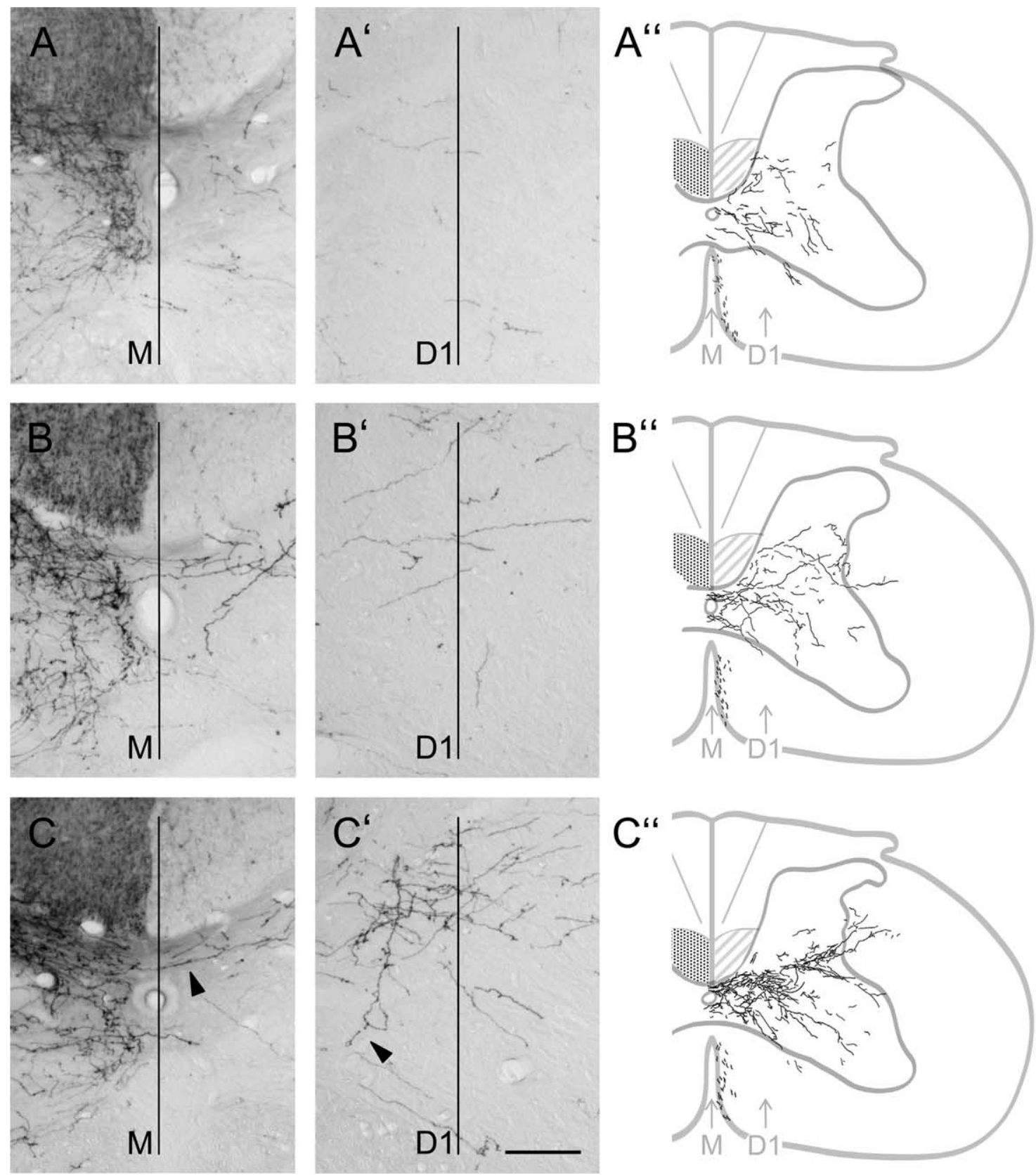

Figure 6. Representative pictures and camera lucida reconstructions of BDA-labeled CST fibers growing toward the contralateral denervated gray matter. Camera lucida reconstructions were made of three consecutive cross sections (50 $\mu \mathrm{m}$; cervical segment (6). BDA-labeled fibers are depicted in black. $A-A^{\prime \prime}$, Intact rat. Few fibers of the intact CST cross the midline at the cervical level (M) to innervate the contralateral gray matter (D1). $\boldsymbol{B}-\boldsymbol{B}^{\prime \prime}$, Pyramidotomy, 3 weeks forced nonuse: Denervation leads to increased growth of fibers over the midline into the contralateral side as well as arborization within the denervated gray matter. $C-C^{\prime \prime}$, Pyramidotomy, 3 weeks forced use: Lesion induced increase of midline-crossing fibers is similar to animals that did not use their impaired limb (compare B, C. Forced limb use leads to a significant increase in arborization of fibers within the denervated gray matter. Growth and sprouting of ipsilateral ventral projections contribute to the increased fiber density. CST fibers also extended arbors deeper into dorsal or ventral laminas. Arrowheads, Midline-crossing fiber, ipsilateral ventral projection. Scale bar, $100 \mu \mathrm{m}$.

$p \leq 0.05)$. Additional information about the regulated genes was obtained from PubMed (http://www.pubmed.com).

\section{Statistical analysis}

All data were analyzed using parametric ANOVA of the appropriate design, followed by restricted analyses or Bonferroni's post hoc pairwise comparisons whenever a main effect or interaction attained statistical significance. All statistical analyses were conducted using the statistical software SPSS (release 14.0). Data are presented as means \pm SEM, single data points represent single animals, and asterisks indicate significances as follows: ${ }^{*} p \leq 0.05 ;{ }^{* *} p \leq 0.01 ;{ }^{* * *} p \leq 0.001$.

\section{Results}

Spontaneous functional recovery after unilateral CST injury Adult female Lewis rats were trained to cross a horizontal ladder with irregular spacing 2 weeks before injury until they were able to perform this task without difficulties. Uninjured animals crossed the ladder at a slow but consistent speed and grasped each rung precisely with all four digits placed in front of the metal bar (Fig. 2A) and had very few misplacements. Errors were always attributable to incorrect placing of single digits but hardly ever to misplacements of the paw on rungs or steps between rungs. The 

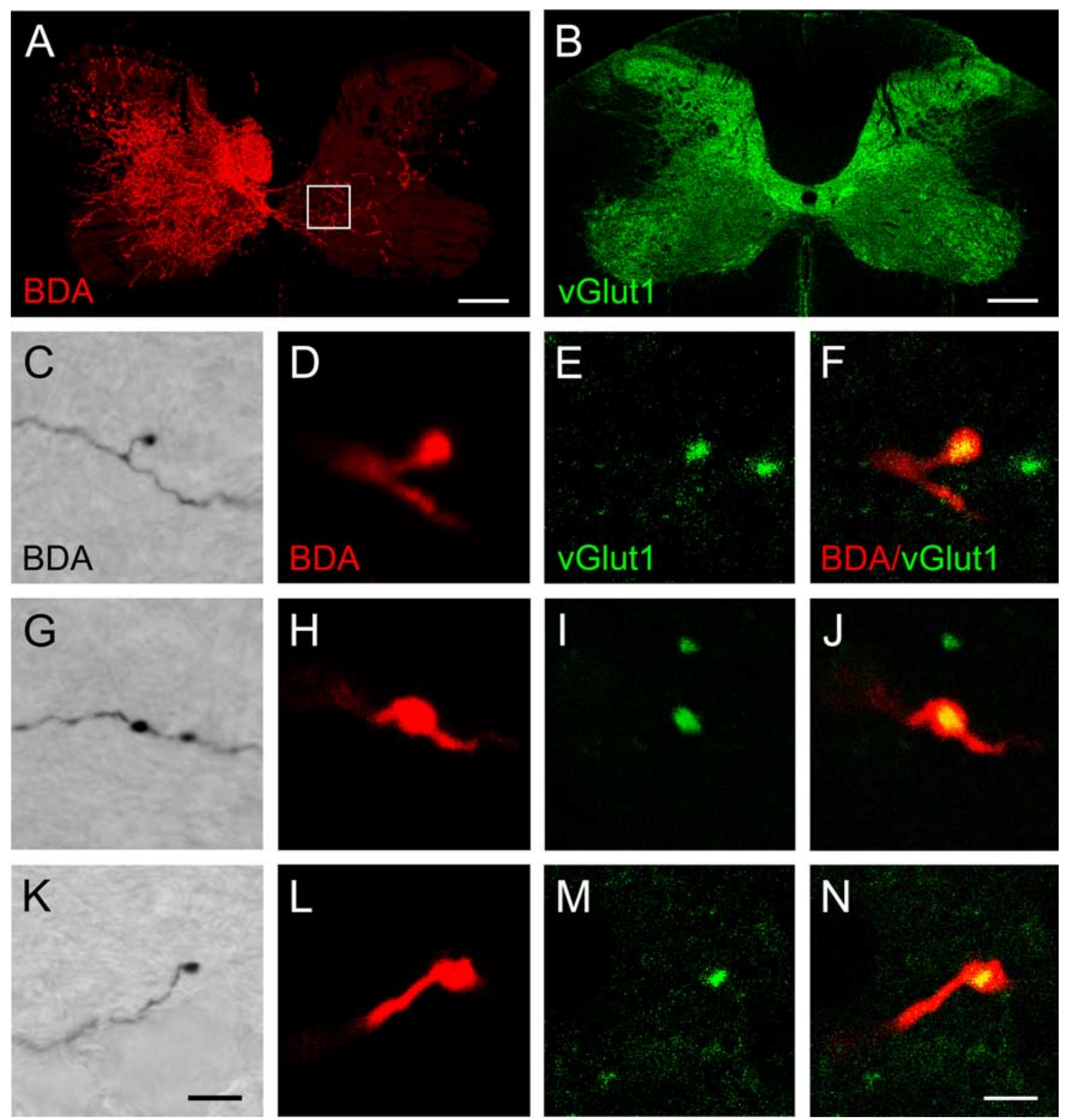

Figure 7. BDA-positive boutons colocalize with vGlut1, a presynaptic marker for excitatory synapses. $C, G, K$, Bouton-like structures were observed along the length and at the tip of BDA-labeled CST collaterals (DAB staining). $A$, Three weeks after injury and forced limb use, CST fibers were labeled with a fluorescent marker for BDA. Fibers were found at high densities within intermediate zone of the denervated spinal cord. Square, Sampling area. $\boldsymbol{D}, \boldsymbol{H}, \boldsymbol{L}, \mathrm{BDA}$ efficiently filled collaterals of corticospinal axons up to their presumed terminal boutons. $\boldsymbol{B}$, Intact animals show vGlut1 immunoreactivity throughout the gray matter, being strongest in superficial laminas and weaker in intermediate and ventral laminas. $E, I, M$, Medium-sized to large vGlut1-positive varicosities were found within the denervated gray matter. $\boldsymbol{F}, \boldsymbol{J}, \boldsymbol{N}$, Confocal microscopy revealed consistent colocalization of BDA and vGlut1. Scale bars: $A, B, 200 \mu \mathrm{m} ; \boldsymbol{C}, \mathbf{G}, \boldsymbol{K}, 5 \mu \mathrm{m} ; \boldsymbol{D}-\boldsymbol{F}, \boldsymbol{H}-\mathbf{J}, \mathbf{L}-\boldsymbol{N}, 2 \mu \mathrm{m}$.

success rate of uninjured animals was high at baseline levels $(90.1 \pm 1.9 \% ; n=7)$. After unilateral CST injury, the contralesional forepaw was severely impaired (Fig. 2E). The following mistakes could be observed: animals misplaced one or more digits behind the rung (Fig. $2 \mathrm{~B}$ ); rats failed to place the palm of their paw directly onto the rung but used their wrist or forearm for support (Fig. 2C); animals misplaced their paw and slipped off the rung or placed their paw between single rungs (Fig. 2D).

To prevent additional training on the horizontal ladder, animals were tested rarely, immediately after injury, and then once per week. Pyramidotomy led to significantly more errors of the impaired forelimb on the horizontal ladder test (ANOVA; $F=$ 113.67; $p \leq 0.001$ ). Spontaneous behavioral improvement was minimal within the next 3 weeks and the success rate remained low (mean success rate, $57.4 \pm 7.6 \%$; Bonferroni's post hoc, $p \leq$ 0.01 ) (Fig. 2E).

\section{Spontaneous growth and arborization of the intact CST} across the midline into the contralateral denervated gray matter

CST fibers originate in layer $\mathrm{V}$ of the primary motor cortex and project to all spinal cord levels through a crossed dorsal component that contains 95\% of all descending axons (Brown, 1971; Schreyer and Jones, 1982) and an ipsilateral ventral component containing $<5 \%$ of all CST axons (Vahlsing and Feringa, 1980; Joosten et al., 1992; Brösamle and Schwab, 2000). Unilateral lesion of the pyramidal tract at the level of the medulla oblongata just rostral to its decussation interrupts both the contralateral as well as the ipsilateral projections to the spinal cord. Lesion completeness was carefully assessed by histological analysis in all animals and in a sample of animals by tracing both sides of the CST (Fig. 3A-C). Animals with incomplete lesions were excluded.

To answer the question whether spontaneous recovery on the 

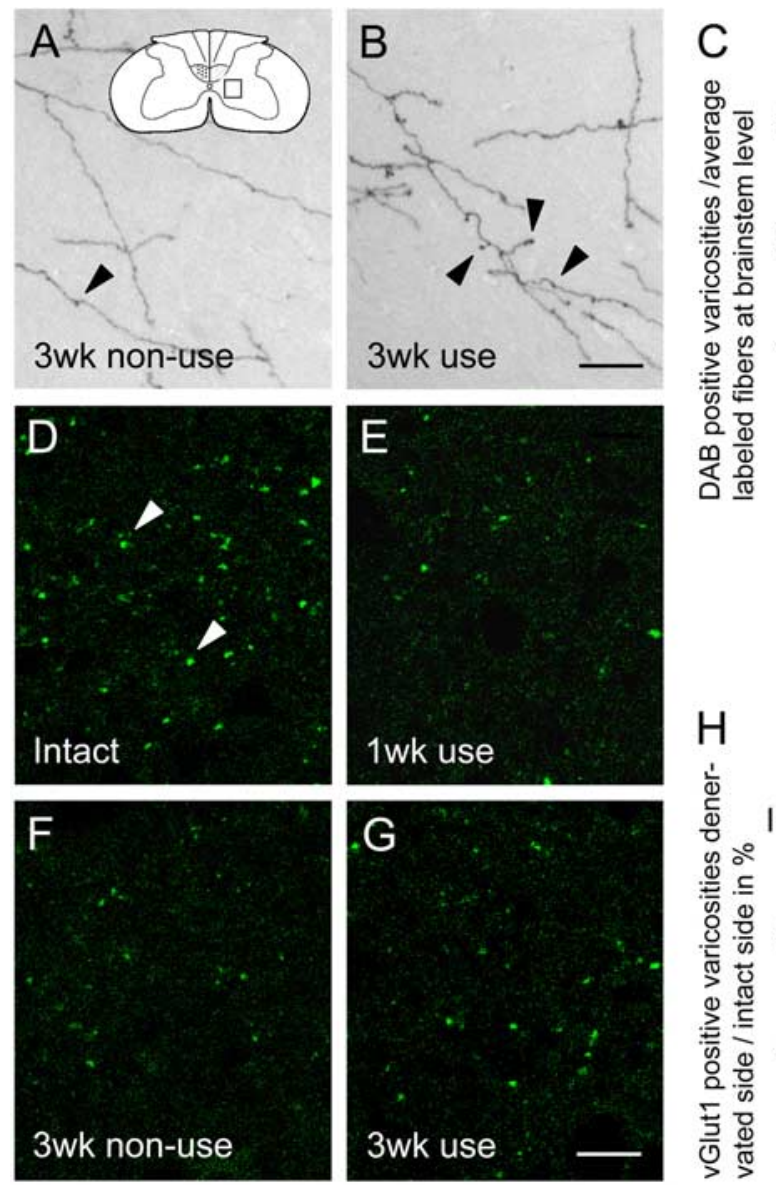

Synaptic boutons
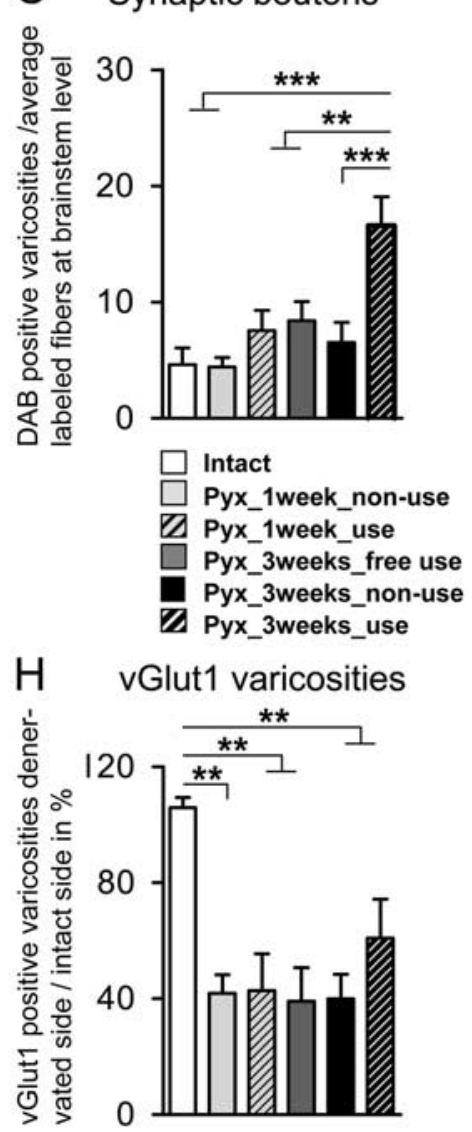

Figure 8. Effect of lesion and forced limb use on the number of synaptic varicosities in the denervated gray matter. $\boldsymbol{C}$, One week after injury, the number of varicosities did not increase in animals that did not use their impaired limb (Pyx_1 week_nonuse; $n=$ 7) or animals that completely relied on their impaired limb (Pyx_1 week_use; $n=7$ ) compared with intact rats (intact; $n=7$ ). After 3 weeks, forced limb use (Pyx_ 3 weeks_use; $n=8$ ) led to a significant increase of boutons per fiber compared with intact, injured but freely moving, unrestricted animals (Pyx_3 weeks_free use) or animals that could not use their impaired limb (Pyx_3 weeks_nonuse; $n=8$ ) (ANOVA, Bonferroni's post hoc, $p \leq 0.001$ ). $\boldsymbol{A}, \boldsymbol{B}$, Representative pictures of BDA-labeled (ST fibers with synaptic boutons in the contralateral gray matter are shown for animals that were restricted from using their impaired limb $(\boldsymbol{A})$ and animals forced to use their impaired $\operatorname{limb}(\boldsymbol{B}) 3$ weeks after injury. $\boldsymbol{A}$, Inset, Schematic drawings of spinal cord cross section with sampling area. Arrowheads, Boutons along CST collaterals. $\boldsymbol{D}-\boldsymbol{H}$, vGlut1-positive varicosities were counted in the intact and the denervated gray matter ( $n=4 /$ group; sampling area A; (6). Denervation led to a significant decrease of vGlut1-positive varicosities at intermediate zone in both groups 1 week after injury $(p \leq 0.01)$. Three weeks after injury, this decrease was still persistent ( $p \leq 0.01$ ) and there was no difference between groups (ANOVA, $p>0.05$ ). Representative pictures of vGlut1positive varicosities in the contralateral gray matter are shown for intact $(\boldsymbol{D})$ and lesioned animals 1 week [forced use $(\boldsymbol{E})$ ] or 3 weeks after injury [forced nonuse $(\boldsymbol{F})$; forced use $(\boldsymbol{G})$ ]. Data are presented as mean \pm SEM. ${ }^{* *} p \leq 0.01 ;{ }^{* * *} p \leq 0.001$. Arrowheads, vGlut1-positive varicosities. Scale bars: $\boldsymbol{A}, \boldsymbol{B}, 20 \mu \mathrm{m} ; \boldsymbol{D}-\mathbf{G}, 10 \mu \mathrm{m}$.

horizontal ladder test was paralleled by compensatory growth of intact CST fibers, the anterograde tracer BDA was injected into the caudal forelimb area of the contralesional sensorimotor cortex. The number of midline-crossing fibers from the labeled intact CST to the denervated side as well as branching of collaterals was evaluated in three experimental groups: unlesioned animals (intact; $n=7$ ), lesioned animals 1 week after injury (Pyx_1 week; $n=5$ ), and lesioned animals 3 weeks after injury (Pyx_3 weeks; $n=7)$.

Growth and sprouting in response to injury was evaluated at the caudal cervical enlargement (C6-C8) where motoneurons innervating forelimb and paw muscles are located (McKenna et al., 2000). Midline-crossing fibers were counted in the dorsal and ventral commissure at the central canal (Fig. 3F, level $\mathrm{M}$ ); branching of these fibers was evaluated at two defined regions within the gray matter (Fig. $3 F$, levels D1 and D2). In intact animals, only few CST fibers crossed the midline and projected into the contralateral gray matter (Fig. 3D,G). One week after injury, there was no significant increase in labeled CST fibers at the midline or within the contralateral denervated gray matter, whereas after 3 weeks the number of CST collaterals projecting and branching within the denervated dorsal, intermediate, and ventral horn was significantly increased in response to injury (ANOVA, Bonferroni's post hoc: $\mathrm{M}, p \leq 0.01 ; \mathrm{D} 1, p \leq$ 0.001 ; D2, $p \leq 0.01$ ) (Fig. $3 E, G$ ). Representative pictures of BDA-labeled CST fibers in the contralateral gray matter are shown for intact (Fig. 3D) or injured animals 3 weeks after CST lesion (Fig. 3E).

\section{Colocalizing the CST tracer BDA and growth cone marker $2 \mathrm{G} 13$}

To investigate whether the increase of labeled CST fibers in the denervated gray matter was attributable to newly grown fibers, we examined whether BDA-positive collaterals expressed the growth cone marker 2G13. 2G13 antibodies have been shown to label axonal growth cones in the developing rat brain in vitro as well as in vivo (Stettler et al., 1999). In P4 rat brain, we observed a high density of 2G13positive, large, growth cone-like structures (Fig. 4A).

In contrast to this, we did not find a constitutive 2G13 expression in the intact adult rat spinal cord or on the intact, nonlesioned side (Fig. 4B). Within the denervated contralateral gray matter of lesioned animals (Fig. 4C,D), 2G13 exclusively labeled short regions of the terminal part of BDA-positive CST collaterals (Fig. 4E,F). Confocal analysis in double-labeled sections revealed a consistent colocalization of BDA and 2G13 1 week (Fig. 4G,H) as well as 3 weeks after injury (Fig. 4I).

\section{Behavioral recovery after \\ pyramidotomy and forced limb use}

To investigate whether spontaneous behavioral recovery after unilateral CST injury could be enhanced by forced use of the impaired forelimb, we used constraint-induced movement therapy (CIMT), a training paradigm previously described in animal models of stroke (Schallert et al., 1997) as well as stroke patients (Taub et al., 1999). Initially, all rats were trained on the horizontal ladder until their success rates were $>90 \%$. They then received a unilateral CST injury by section of one pyramid, as described above. Immediately after injury, one-holed vests of plaster cast were formed around their upper torso, which forced the animals to completely rely either on their impaired or their nonimpaired forelimb. To investigate the influence of time on behavioral recovery, animals were subdivided into the following four groups: rats that could not use their impaired limb for either one (Pyx_1 week_nonuse; $n=7$ ) or 3 weeks (Pyx_3 weeks_nonuse; $n=8$ ) and animals that were forced to rely on their impaired side for 
either one (Pyx_1 week_use; $n=7$ ) or 3 weeks, respectively (Pyx_3 weeks_use; $n=$ $8)$. Finally, the cast was carefully removed and all animals were allowed to recover for $48 \mathrm{~h}$ before locomotor performance of their impaired limb was tested once on the horizontal ladder. Unilateral CST injury led to more errors on the horizontal ladder test (ANOVA; $F=134.21 ; p \leq 0.001)$ with a significant difference between groups $(F=59.27 ; p \leq 0.001)$ (Fig. 5A). One week after injury, animals that were not able to use their impaired forelimb had a lower success rate $(60.4 \pm 5.5 \%)$ compared with animals that were forced to rely on their impaired forelimb $(80.2 \pm 2.2 \%$; Bonferroni's post hoc, $p \leq 0.01$ ). This was even more prominent when rats had to wear their cast for a longer time period: Animals that were forced to completely rely on their impaired forelimb for 3 weeks regained their prelesion baseline performance level (success rate, $91.9 \pm 3.3 \%$ ), whereas animals that could not use their impaired forelimb remained significantly impaired (success rate, $63.0 \pm 3.7 \%$; Bonferroni's post hoc, $p \leq 0.001$ ).

To control for the effect of possible muscle atrophy and stiffness of the casted limb on locomotor performance, two additional groups of animals received a sham operation followed by a cast for 3 weeks. The cast was removed and either the restricted limb (sham_nonuse; $n=6$ ) or the unrestricted limb (sham_use; $n=9$ ) was tested for errors on the horizontal ladder (Fig. 5B). Our results show no differences in the success rate between the casted or the noncasted intact forelimb and no decrease of locomotor performance in response to sham surgery (ANOVA, $p>$ 0.05) (Fig. 5B).

\section{Growth and arborization of CST fibers in response to forced limb use}

To investigate whether forced limb use can influence fiber growth in the denervated spinal cord, the intact CST was traced in all animals and midlinecrossing fibers as well as arborization of fibers in the ventral gray matter was evaluated as described above (Fig. $3 F$ ). We did not observe differences between spinal cords 1 week after injury (Fig. $5 C$ ); also, fiber counts were very similar to those of lesioned but uncasted animals (compare Figs. 5C, 3G). After 3 weeks, significantly more CST collaterals crossed the midline and arborized within the denervated gray matter in response to injury (ANOVA, $p \leq 0.001$ ). Forced limb use led to an additional, significant increase of labeled fibers in the denervated gray matter compared with spinal cords of animals that could not use their impaired limb (Bonferroni's post hoc: D1, $p \leq 0.01 ; \mathrm{D} 2, p \leq 0.05$ ) similar to the amount of growth and

A

C
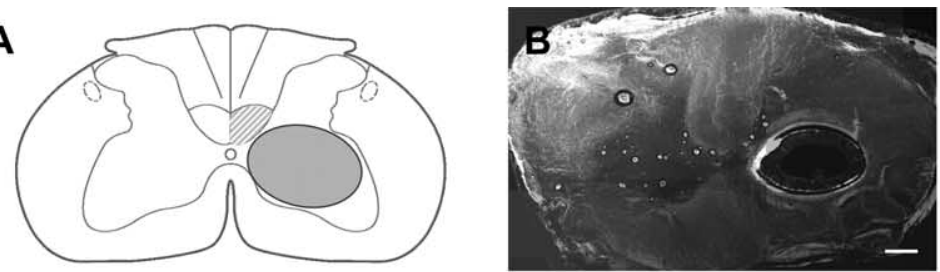

Genes regulated in response to forced limb use

\begin{tabular}{lll} 
Genes regulated & $\mathbf{2 2 3}$ & $\mathbf{2 4 9}$ \\
Upregulated $\geq 1.2$ & 136 & 154 \\
Downregulated $\leq 0.8$ & 87 & 95 \\
\hline Category & $\%$ & $\%$ \\
Signalling & 13.5 & 16.9 \\
Transcription & 10.3 & 8.8 \\
Protein synthesis & 3.6 & 2.8 \\
Channel function & 1.3 & 3.2 \\
Cytoskeleton & 4.9 & 3.2 \\
Inflammation & 2.7 & 4.4 \\
Metabolism & 3.6 & 3.6 \\
Mitochondrial & 0.0 & 2.0 \\
Protease & 5.8 & 2.0 \\
Transport & 2.7 & 0.8 \\
Apoptosis/Stress & 2.2 & 0.8 \\
Heatshock protein & 1.8 & 0.4 \\
Guidance & 0.9 & 0.8 \\
Adhesion & 7.1 & 8.0 \\
Synapses & 0.9 & 5.2 \\
Growth & 0.4 & 2.8 \\
Other & 38.4 & 34.1 \\
& & \\
\hline
\end{tabular}

Sham

Pyramidotomy
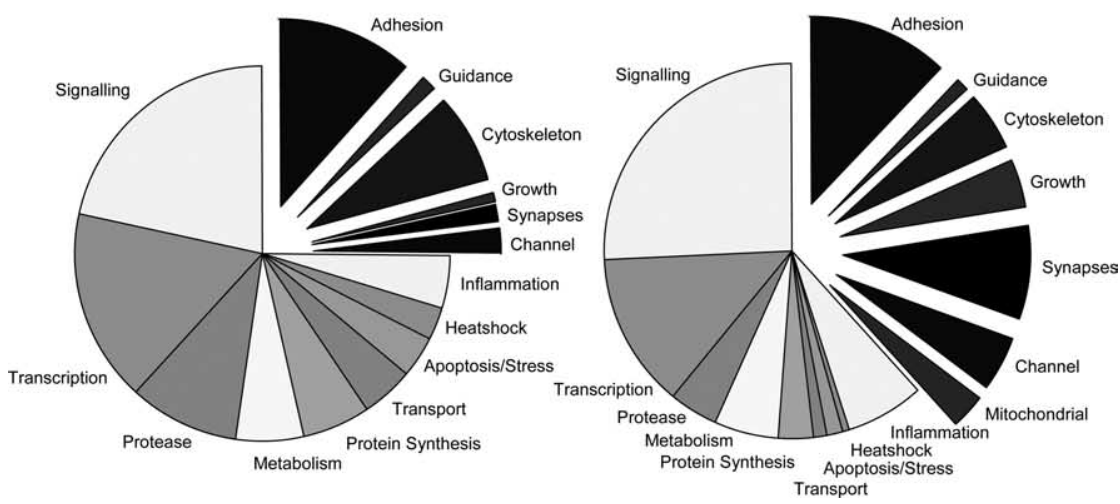

Figure 9. Microdissection and gene chip analysis of the denervated ventral horn. $A$, Schematic drawing of cross section with the extracted area. $\boldsymbol{B}$, Spinal cord cross section with extracted ventral horn ( $250 \mu \mathrm{m}$; fresh tissue). $\boldsymbol{C}$, Differentially regulated genes (forced limb use compared with forced nonuse) were sorted in 17 categories, and the number of regulated genes and percentages are shown for sham-operated animals as well as lesioned animals forced to rely on their impaired limb or animals that could not use their impaired limb in a table and a graphical representation. Note the high proportion of genes involved in growth, cytoskeletal reorganization, adhesion, and synapse formation in response to forced limb use in the denervated gray matter. Scale bar, $100 \mu \mathrm{m}$. arborization previously observed in lesioned, unconstrained animals (compare Figs. 5C, 3G). Interestingly, 3 weeks of forced use alone did not increase the number of midlinecrossing fibers or axonal arbors in intact sham-operated animals (Fig. 5D) ( $p>0.05)$.

To give an overall impression of the extent and specificity of CST fiber growth in intact and lesioned animals, representative pictures and camera lucida reconstructions of three consecutive cross sections are shown in Figure 6. BDA injections into the 
Table 1. List of genes regulated $\geq 1.2$ - or $\leq 0.8$-fold in the ventral gray matter after forced limb use in comparison with forced nonuse (sham-operated animals)

\begin{tabular}{|c|c|c|}
\hline Description & Gene symbol & Fold change \\
\hline \multicolumn{3}{|l|}{ Signaling } \\
\hline 5-Hydroxytryptamine (serotonin) receptor 7 & Htr7 & 1.49 \\
\hline Adenylate kinase 2 & $A k 2$ & 1.23 \\
\hline ADP-ribosylation factor-like 5 & Arl5 & 1.36 \\
\hline ATP/GTP binding protein 1 (predicted) & Agtpbp1_predicted & 1.30 \\
\hline Casein kinase II, $\alpha 1$ polypeptide & Csnk2a1 & 1.26 \\
\hline Cdc42-binding protein kinase $\beta$ & $C d c 42 b p b$ & 0.64 \\
\hline Cyclin D3 & Cend3 & 1.26 \\
\hline Ganglioside-induced differentiation-associated protein 1-like 1 (predicted) & Gdap1I_predicted & 0.72 \\
\hline Guanine monphosphate synthetase (predicted) & Gmps_predicted & 1.21 \\
\hline Guanine nucleotide binding protein, $\beta 1$ & Gnb1 & 1.29 \\
\hline Ligatin, similar to & LOC498225 & 1.26 \\
\hline Peroxisome biogenesis factor 5 (predicted) & Pex5_predicted & 0.77 \\
\hline Poliovirus receptor-related 3 (predicted) & Pvrl3_predicted & 1.38 \\
\hline Protein kinase C binding protein 1 (predicted) & Prkcbp1_predicted & 1.72 \\
\hline Protein kinase $C, \beta 1$ & Prkcb1 & 0.62 \\
\hline Protein kinase $C, \beta 1$ & Prkcb1 & 0.26 \\
\hline Protein kinase, AMP-activated, $\gamma 2$ noncatalytic subunit & Prkag2 & 1.29 \\
\hline Protein kinase, cAMP-dependent, regulatory, type $2, \alpha$ & Prkar2a & 1.27 \\
\hline Protein phosphatase 1, regulatory (inhibitor) subunit 12A & Ppp1r12a & 1.38 \\
\hline Putative zinc finger protein, similar to & Dus3l & 1.20 \\
\hline Pyruvate dehydrogenase kinase, isoenzyme 2 & Pdk2 & 0.73 \\
\hline RAB, member of RAS oncogene family-like 3 (predicted) & Rabl3_predicted & 1.29 \\
\hline Rapostlin & Fnbp1 & 0.75 \\
\hline Ras association (RaIGDS/AF-6) domain family 4 (predicted) & Rassf4_predicted & 1.31 \\
\hline RAS guanyl releasing protein 1 & Rasgrp1 & 1.24 \\
\hline Ras-like without CAAX 1 (predicted) & Rit1_predicted & 1.21 \\
\hline Ras-related protein Rab-1B, similar to & $R G D: 1359415$ & 0.70 \\
\hline Serine/arginine-rich protein specific kinase 2 (predicted) & Srpk2_predicted & 1.29 \\
\hline Sprouty protein with EVH-1 domain 1, related sequence (predicted) & Spred1 & 1.25 \\
\hline Transcription factor EB (predicted) & Tcfeb_predicted & 0.68 \\
\hline \multicolumn{3}{|l|}{ Transcription } \\
\hline Transducin-like enhancer of split 3, E(spl) homolog (Drosophila) & Tle3 & 0.78 \\
\hline N-terminal enhancer of split & Aes & 0.79 \\
\hline Conserved helix-loop-helix ubiquitous kinase (predicted) & Chuk_predicted & 1.46 \\
\hline Euchromatic histone methyltransferase 1 (predicted) & Ehmt1_predicted & 1.39 \\
\hline Exportin 4 (predicted) & Xpo4_predicted & 1.24 \\
\hline Heat shock transcription factor 1 & Hsf1 & 0.78 \\
\hline Histone 2, H2aa (predicted); similar to Hist2h2aa1 protein & Hist2h2aa_predicted & 0.78 \\
\hline Histone deacetylase 1 (predicted) & Hdac1_predicted & 1.26 \\
\hline Homeobox B8 & Hoxb8 & 0.60 \\
\hline Inhibitor of DNA binding 2, dominant-negative helix-loop-helix protein & Id 2 & 0.75 \\
\hline LIM homeobox protein 5 & Lhx 5 & 0.55 \\
\hline Mouse zinc finger protein 14-like & LOC499124 & 1.30 \\
\hline Nuclear receptor corepressor 1 & Ncor1 & 1.70 \\
\hline Nucleolar protein (NOL1/NOP2/sun) and PUA domains 1 (predicted) & Nopd1_predicted & 1.30 \\
\hline Putative homeodomain transcription factor 2 (predicted) & Phtf2_predicted & 1.30 \\
\hline Retinoblastoma-like 2 & $\mathrm{Rb} / 2$ & 1.23 \\
\hline Ribonucleic acid binding protein S1 (predicted) & Rnps1_predicted & 1.36 \\
\hline Sulfotransferase family, cytosolic, 1C, member 2 & Sult1c2 & 2.77 \\
\hline Thyroid hormone receptor associated protein 1 (predicted) & Thrap1_predicted & 1.46 \\
\hline Transcription factor RAM2, similar to & LOC619566 & 1.32 \\
\hline Upstream transcription factor 2 & Usf2 & 0.72 \\
\hline Zinc finger proliferation 1 (predicted) & Zipro1_predicted & 1.30 \\
\hline Zinc finger protein 14 (KOX 6) & Znf14 & 1.46 \\
\hline \multicolumn{3}{|l|}{ Protein synthesis } \\
\hline Zinc finger, FYVE domain containing 20 (predicted) & Zfyve20_predicted & 1.22 \\
\hline Amyloid $\beta(A 4)$ precursor-like protein 2 & Aplp2 & 1.21 \\
\hline Coilin & Coil & 1.61 \\
\hline DEAD (Asp-Glu-Ala-Asp) box polypeptide 41 (predicted) & Ddx41_predicted & 1.29 \\
\hline DEAD/H (Asp-Glu-Ala-Asp/His) box polypeptide 26 (predicted) & $D d x 26$ & 1.48 \\
\hline Glutamate-cysteine ligase, catalytic subunit & Gclc & 1.33 \\
\hline Longevity assurance homolog 4 (S. cerevisiae) (predicted) & Lass4_predicted & 0.63 \\
\hline Stearoyl-coenzyme A desaturase 1 & Scd1 & 0.75 \\
\hline Stearoyl-coenzyme A desaturase 2 & $\mathrm{Scd} 2$ & $\begin{array}{l}0.60 \\
\text { ble continues.) }\end{array}$ \\
\hline
\end{tabular}


Table 1. Continued

\begin{tabular}{|c|c|c|}
\hline Description & Gene symbol & Fold change \\
\hline \multicolumn{3}{|l|}{ Channel } \\
\hline Putative chloride channel (similar to Mm Clen4-2) & RGD:708381 & 1.24 \\
\hline Solute carrier family 3, member 1 & SIc3a1 & 1.32 \\
\hline Solute carrier family 6 (neurotransmitter transporter, glycine), member 9 & Slc6a9 & 0.72 \\
\hline \multicolumn{3}{|l|}{ Cytoskeleton } \\
\hline ARP5 actin-related protein 5 homolog (yeast) (predicted) & Actr5_predicted & 0.83 \\
\hline Calponin 3, acidic & $\mathrm{Cnn} 3$ & 0.78 \\
\hline Cytoplasmic linker associated protein 1 (predicted) & Clasp1_predicted & 1.25 \\
\hline Enabled homolog (Drosophila) (predicted) & Enah_predicted & 1.29 \\
\hline Filamin C, $\gamma$ (actin binding protein 280) (predicted) & Flnc_predicted & 0.58 \\
\hline Multiple hat domains (predicted), similar to & RGD1311017_predicted & 1.39 \\
\hline Myristoylated alanine rich protein kinase C substrate & Marcks & 0.77 \\
\hline Neurofilament triplet $\mathrm{H}$ protein (predicted), similar to & RGD1311283_predicted & 1.31 \\
\hline Profilin 1 & Pfn1 & 0.79 \\
\hline Septin 6 (predicted) & Sept6_predicted & 1.24 \\
\hline \multicolumn{3}{|l|}{ Inflammation } \\
\hline Tropomodulin 4 (predicted) & Tmod4_predicted & 1.29 \\
\hline Interleukin-1 receptor-associated kinase 1 binding protein 1 (predicted) & Irak1bp1_predicted & 1.27 \\
\hline Lymphocyte antigen 6 complex, locus $\mathrm{H}$ (predicted) & Ly6h_predicted & 0.77 \\
\hline Lymphotoxin B receptor (predicted) & Ltbr_predicted & 0.83 \\
\hline RT1 class $I b$, locus $S 3$ & RTI-S3 & 1.29 \\
\hline Toll-like receptor 4 & TIr4 & 1.93 \\
\hline \multicolumn{3}{|l|}{ Metabolism } \\
\hline Tumor necrosis factor (ligand) superfamily, member 9 & Tnfsf9 & 0.77 \\
\hline Creatine kinase, mitochondrial 2, sarcomeric & Ckmt2 & 1.33 \\
\hline 3-Hydroxy-3-methylglutaryl-coenzyme A reductase & Hmgcr & 1.43 \\
\hline Lactate dehydrogenase $\mathrm{D}$ (predicted) & Ldhd_predicted & 0.81 \\
\hline Mannosidase, $\alpha$, class $2 C$, member 1 & $\operatorname{Man} 2 \mathrm{C1}$ & 0.83 \\
\hline \multicolumn{3}{|l|}{ Mitochondrial } \\
\hline RI0 kinase 1 (yeast) (predicted) & Riok1_predicted & 1.42 \\
\hline Aconitase 2, mitochondrial & AcO2 & 1.77 \\
\hline \multicolumn{3}{|l|}{ Protease } \\
\hline Mitochondrial ribosomal protein L51 (predicted) & Mrpl51_predicted & 1.32 \\
\hline Echinoderm microtubule associated protein like 4 (predicted) & Eml4_predicted & 1.39 \\
\hline Glutamyl aminopeptidase & Enpep & 1.22 \\
\hline Hect [homologous to the E6-AP (UBE3A) carboxyl terminus] domain (predicted) & Herc1_predicted & 1.36 \\
\hline Proteasome (prosome, macropain) 265 subunit, non-ATPase, 4 & Psmd4 & 2.07 \\
\hline Reversion-inducing-cysteine-rich protein with kazal motifs (predicted) & Reck_predicted & 1.31 \\
\hline Subtilisin-like endoprotease & Pace4 & 0.78 \\
\hline Tripartite motif protein 25 & Trim25 & 1.23 \\
\hline Ubiquitin ligase protein DZIP3 (DAZ-interacting protein 3 homolog), similar to & LOC303963 & 1.30 \\
\hline Ubiquitin protein ligase E3A (predicted) & Ube3a_predicted & 1.38 \\
\hline Ubiquitin specific protease 29 (predicted) & Usp29_predicted & 0.80 \\
\hline Ubiquitin specific protease 49 (predicted) & Usp49_predicted & 1.22 \\
\hline Ubiquitin specific protease 8 (predicted) & Usp8_predicted & 1.67 \\
\hline \multicolumn{3}{|l|}{ Transport } \\
\hline YME1-like 1 (S. cerevisiae) & Yme1/1 & 1.37 \\
\hline Aryl hydrocarbon receptor-interacting protein-like 1 & Aipl1 & 0.17 \\
\hline Apolipoprotein C-I & Apoc1 & 0.54 \\
\hline Dynamin 1-like & Dnm1I & 1.41 \\
\hline Dynein, cytoplasmic, light intermediate chain 1 & Dncli1 & 1.23 \\
\hline Kinesin light chain 3 & Klc3 & 0.80 \\
\hline \multicolumn{3}{|l|}{ Apoptosis/stress } \\
\hline Vesicle-associated calmodulin-binding protein & $R G D: 621488$ & 0.74 \\
\hline BH3 interacting domain death agonist & Bid & 1.56 \\
\hline Neurogenic differentiation 1 & Neurod1 & 1.54 \\
\hline PERP, TP53 apoptosis effector (predicted) & Perp_predicted & 0.73 \\
\hline Poly $(\mathrm{rC})$ binding protein 4 (predicted) & Pcbp4_predicted & 0.77 \\
\hline Regulator of Fas-induced apoptosis; Fas apoptotic inhibitory molecule, similar to & LOC498224 & 0.74 \\
\hline \multicolumn{3}{|l|}{ Heat shock protein } \\
\hline DnaJ (Hsp40) homolog, subfamily B, member 6 (predicted) & Dnajb6 & 1.30 \\
\hline DnaJ (Hsp40) homolog, subfamily C, member 2 & Zrf2 & 1.87 \\
\hline Heat shock 70 kDa protein 5 & Hspa5 & 1.23 \\
\hline \multicolumn{3}{|l|}{ Guidance } \\
\hline Heat shock protein hsp70-related protein & RGD:1303296 & 1.20 \\
\hline Collapsin response mediator protein- $2 \mathrm{~A}$, similar to & Dpys/2 & $\begin{array}{c}1.27 \\
\text { (Table continues.) }\end{array}$ \\
\hline
\end{tabular}




\begin{tabular}{|c|c|c|}
\hline Description & Gene symbol & Fold change \\
\hline \multicolumn{3}{|l|}{ Adhesion } \\
\hline Sema domain, transmembrane domain (TM), and cytoplasmic domain, (semaphorin) 6C & Sema6c & 0.71 \\
\hline Abelson murine leukemia viral (v-abl) oncogene homolog 1 & Abl1 & 0.78 \\
\hline Chondroitin sulfate proteoglycan 5 & Cspg5 & 0.71 \\
\hline Ephrin A1 & Efna1 & 1.27 \\
\hline Extracellular matrix protein 2, female organ and adipocyte specific (predicted) & Ecm2_predicted & 1.67 \\
\hline Fibrillin 1 & Fbn1 & 0.67 \\
\hline Fibromodulin & Fmod & 1.49 \\
\hline Laminin, $\alpha 2$ (predicted) & Lama2_predicted & 1.25 \\
\hline Matrix metallopeptidase 2 & Mmp2 & 1.49 \\
\hline Procollagen, type IX, $\alpha 2$ (predicted) & Col9a2_predicted & 0.77 \\
\hline Protocadherin 16 dachsous-like (Drosophila) (predicted) & Dchs1_predicted & 0.74 \\
\hline Secreted phosphoprotein 1 & Spp1 & 1.26 \\
\hline Similar to chondroitin $\beta 1,4 \mathrm{~N}$-acetylgalactosaminyltransferase (predicted) & RGD1307618_predicted & 1.42 \\
\hline Similar to establishment of cohesion 1 homolog 2 & LOC498536 & 1.71 \\
\hline Tenascin XA & Tnxa & 0.82 \\
\hline Transmembrane 7 superfamily member 1 (predicted) & Tm7sf1_predicted & 0.79 \\
\hline \multicolumn{3}{|l|}{ Synapses } \\
\hline Synaptojanin 2 binding protein & Synj2bp & 1.22 \\
\hline Synaptotagmin 2 & Syt2 & 0.79 \\
\hline \multicolumn{3}{|l|}{ Growth } \\
\hline Myelin basic protein & $M b p$ & 1.23 \\
\hline
\end{tabular}

Shown are differentially regulated genes (sham-operated animals, restricted side in comparison with unrestricted side) belonging to the categories of signaling, transcription, protein synthesis, channel, cytoskeleton, inflammation, metabolism, mitochondrial, protease, transport, apoptosis, stress, heat shock protein, guidance, adhesion, synapse formation, and growth that show fold changes of $\geq 1.2$ or $\leq 0.8$ (upregulated genes are in bold).

sensorimotor cortex label projections to the dorsal as well as ventral horn of the spinal cord. In intact animals, very few CST collaterals crossed the midline to innervate the contralateral gray matter (Fig. $\left.6 A-A^{\prime \prime}\right)$. Injury induced spontaneous growth of new fibers across the midline as well as arborization of these collaterals and/or preexisting fibers within the denervated gray matter. In addition, camera lucida reconstructions clearly demonstrate a contribution of ipsilateral ventral projections to the increased innervation in the denervated gray matter. CST axons not only increased their innervation area in response to injury by local arborization but they also extended arbors deeper into dorsal or ventral laminas as shown in animals that could not use their impaired side for 3 weeks (Fig. $6 B-B^{\prime \prime}$ ). Casted animals that were forced to completely rely on their impaired limb for 3 weeks showed similar growth across the midline but significantly more arborization within the intermediate zone as well as longer branches into the denervated dorsal and ventral horn (Fig. $\left.6 C-C^{\prime \prime}\right)$.

\section{Midline-crossing CST fibers form glutamatergic synapses}

CST collaterals within the denervated spinal cord (Fig. 7A) frequently showed bouton-like structures along their length (en passant) and at their tips (bouton terminal) (Fig. 7C, G, K). We colocalized BDA with vGlut1, a marker enriched in corticospinal synapses (Varoqui et al., 2002; Persson et al., 2006). BDA efficiently filled collaterals of corticospinal axons up to their presumed terminal boutons (Fig. $7 D, H, L$ ).

vGlut1 immunoreactivity was found throughout the gray matter being strongest in superficial laminas and weaker in intermediate and ventral laminas (Fig. 7B). The distribution pattern was consistent with termination zones of primary afferents, CST, probably brainstem-spinal and other fiber systems (Persson et al., 2006). Medium- to large-sized vGlut1positive varicosities were present at a moderate density throughout most of lamina VII (Fig. $7 E, I, M$ ). Confocal microscopy revealed that BDA-positive en passant and terminal varicosities were positive for vGlut1 immunoreactivity, sug- gesting they are presynaptic glutamatergic boutons (Fig. $7 F, J, N)$.

\section{Synapse formation after forced limb use}

To answer the question whether forced limb use has an influence on synapse formation, bouton-like structures were counted in lamina VII of the denervated gray matter in five different groups: intact animals (intact; $n=7$ ), injured animals without any constraints (Pyx_3 weeks_free use; $n=7$ ), as well as animals that could not use their impaired limb for either 1 week (Pyx_1 week_nonuse; $n=7$ ) or 3 weeks (Pyx_3 weeks_nonuse; $n=8$ ) and animals forced to rely on their impaired side for 1 week (Pyx_1 week_use; $n=7$ ) or 3 weeks (Pyx_3 weeks_use; $n=8$ ). In accordance with the low number of midline-crossing CST fibers in intact rats, we found only few BDA-positive synapses in the contralateral gray matter. One week after injury, the number of varicosities per labeled fiber did not increase in animals that used their impaired limb or animals that could not use their impaired limb. After 3 weeks, animals that were forced to rely on their impaired limb showed a significant increase in the number of boutons (ANOVA, followed by Bonferroni's post hoc, $F=8.826$; $p \leq$ 0.001 ) (Fig. $8 A-C$ ). Interestingly, injured rats without constraints as well as animals with their impaired forelimb casted completely lacked this increase.

The density of vGlut 1-positive varicosities was determined in lamina VII of the intact and the denervated gray matter. Because vGlut1 does not exclusively label CST terminations but also primary afferents and other descending fiber tracts, our analysis reflects a general change of excitatory input at the intermediate zone. Uninjured animals showed an equal distribution of vGlutl on both sides of the cervical spinal cord. One week after CST transection, the density of vGlut1-positive varicosities on the denervated intermediate gray matter was reduced to $\sim 40 \%$. This reduction persisted up to 3 weeks after injury (ANOVA; $F=8.38 ; p \leq 0.01$ ). The density of vGlut1-positive structures appeared higher in animals that 
Table 2. List of genes regulated $\geq 1.2$ - or $\leq 0.8$-fold in the denervated ventral gray matter after forced limb use in comparison with forced nonuse (injured animals)

\begin{tabular}{|c|c|c|}
\hline Description & Gene symbol & Fold change \\
\hline \multicolumn{3}{|l|}{ Signaling } \\
\hline A kinase (PRKA) anchor protein 5 & Akap5 & 0.73 \\
\hline Adenylate kinase 7 (predicted) & Ak7_predicted & 0.66 \\
\hline ADP-ribosylation factor-like 12 (predicted) & Arl12_predicted & 1.46 \\
\hline ADP-ribosyltransferase 3 (predicted) & Art3_predicted & 0.81 \\
\hline Amyotrophic lateral sclerosis 2 (juvenile) (predicted) & Als2_predicted & 0.83 \\
\hline Ariadne homolog 2 (Drosophila) (predicted) & Arih2_predicted & 1.36 \\
\hline Calcium/calmodulin-dependent protein kinase IV & Camk4 & 1.51 \\
\hline Casitas B-lineage lymphoma b & Cblb & 0.79 \\
\hline CDC42 effector protein (Rho GTPase binding) 5 (predicted) & Cdc42ep5_predicted & 0.80 \\
\hline Coagulation factor II (thrombin) receptor & $F 2 r$ & 0.81 \\
\hline Copine III (predicted) & Cpne3_predicted & 0.69 \\
\hline Cyclin D2 & Cond2 & 0.82 \\
\hline Death-associated protein kinase 1 (predicted) & Dapk1_predicted & 0.77 \\
\hline Ectonucleotide pyrophosphatase/phosphodiesterase 3 & Enpp3 & 0.65 \\
\hline Exportin 4 (predicted) & Xp04_predicted & 0.75 \\
\hline FL23471 protein (predicted) similar to & RGD1307875_predicted & 0.70 \\
\hline FK506 binding protein 5 (predicted) & Fkbp5_predicted & 1.34 \\
\hline Fring & Rffl & 0.83 \\
\hline G protein-coupled receptor 21 (predicted) & Gpr21_predicted & 0.79 \\
\hline GTP binding protein (gene overexpressed in skeletal muscle) (predicted) & Gem_predicted & 1.22 \\
\hline GTPase, IMAP family member 5 & Gimap5 & 0.71 \\
\hline Heme oxygenase 3 ( $\mathrm{HO}-3$ ) similar to & LOC365909 & 2.64 \\
\hline Inositol 1,4,5-triphosphate receptor 3 & Itpr3 & 1.24 \\
\hline Mastermind like 1 (Drosophila) (predicted) & Mam/1_predicted & 0.73 \\
\hline Mitogen-activated protein kinase 10 & Mapk10 & 1.23 \\
\hline MOB1, Mps One Binder kinase activator-like 2B (yeast) (predicted) & Mobkl2b_predicted & 1.76 \\
\hline Nuclear ubiquitous casein kinase and cyclin-dependent kinase substrate & Nucks & 0.75 \\
\hline Phosphatase and tensin homolog & Pten & 1.21 \\
\hline Prolactin receptor & Prlr & 1.53 \\
\hline Proline-serine-threonine phosphatase-interacting protein 1 (predicted) & Pstpip1_predicted & 1.23 \\
\hline Protein kinase C binding protein 1 (predicted) & Prkcbp1_predicted & 0.75 \\
\hline Protein phosphatase 1, regulatory (inhibitor) subunit 3B & Ppp1r3b & 1.47 \\
\hline Protein phosphatase 2 , regulatory subunit $B(B 56), \delta$ isoform (predicted) & Ppp2r5d_predicted & 0.81 \\
\hline Protein phosphatase $2 \mathrm{C} \zeta$ & RGD:1359104 & 1.37 \\
\hline Protein phosphatase 5 , catalytic subunit & Ppp5c & 1.52 \\
\hline Rab40b, member RAS oncogene family (predicted) & Rab40b_predicted & 0.78 \\
\hline RAB6A, member RAS oncogene family & $\operatorname{Rab6}^{-1}$ & 0.76 \\
\hline RAP2B, member of RAS oncogene family & $\operatorname{Rap} 2 b$ & 1.87 \\
\hline RAS guanyl releasing protein 2 (calcium and DAG-regulated) (predicted) & Rasgrp2_predicted & 0.75 \\
\hline Rho GTPase activating protein 20; hypothetical gene supported by NM_213629 & Arhgap20; LOC497830 & 1.35 \\
\hline Secreted frizzled-related protein 2 & Sfrp2 & 0.59 \\
\hline Yamaguchi sarcoma viral (v-yes-1) oncogene homolog & Lyn & 1.70 \\
\hline \multicolumn{3}{|l|}{ Transcription } \\
\hline Adenosine $A 2 B$ receptor & Adora $2 b$ & 0.83 \\
\hline Activating transcription factor 7 interacting protein (predicted) & Atf7ip_predicted & 1.50 \\
\hline AP1 $\gamma$ subunit binding protein 1 & Ap1gbp1 & 1.31 \\
\hline B-cell CLL/lymphoma 11A (zinc finger protein) (predicted) & Bcl11a & 0.63 \\
\hline Fragile $\mathrm{X}$ mental retardation gene 2 , autosomal homolog (predicted) & Fxr2h_predicted & 1.29 \\
\hline Heterogeneous nuclear ribonucleoprotein methyltransferase-like 3 (S. cerevisiae) & Prmt3 & 1.87 \\
\hline Histone $\mathrm{H} 4$ variant $\mathrm{H} 4$-v0.1; similar to germinal histone $\mathrm{H} 4$ gene & LOC500351 & 1.35 \\
\hline Meningioma expressed antigen 5 (hyaluronidase) & Mgea5 & 1.22 \\
\hline Myelin transcription factor 1-like & Myt11 & 0.83 \\
\hline Nuclear transcription factor, X-box binding 1 (predicted) & Nfx1_predicted & 0.82 \\
\hline Nuclear receptor subfamily 1 , group D, member 1 & $\operatorname{Nr} 1 d 1$ & 0.81 \\
\hline Retinoblastoma-like 2 & Rbl2 & 1.40 \\
\hline RNA-binding region (RNP1, RRM) containing 2 (predicted) & Rnpc2_predicted & 0.72 \\
\hline Scratch homolog 1, zinc finger protein (Drosophila) (predicted) & Scrt1_predicted & 1.31 \\
\hline SP110 nuclear body protein (predicted) & Sp110 & 0.72 \\
\hline SOX2 protein similar to & LOC499593 & 0.78 \\
\hline Speedy homolog 1 (Drosophila) & Spdy1 & 0.60 \\
\hline Sperm 1 POU-domain transcription factor (SPRM-1) (predicted) & RGD1305526_predicted & 1.73 \\
\hline SWI/SNF related, matrix associated, actin dependent regulator of chromatin, subfamily a, member 4 & Smarca4 & 0.81 \\
\hline Transcription factor CP2 (predicted) & Tffcp2_predicted & 1.33 \\
\hline Transcription factor A, mitochondrial & Tfam & 0.82 \\
\hline Tumor suppressor candidate 4 (predicted) & Tusc4_predicted & $\begin{array}{c}1.29 \\
\text { (Table continues.) }\end{array}$ \\
\hline
\end{tabular}


Table 2. Continued

\begin{tabular}{|c|c|c|}
\hline Description & Gene symbol & Fold change \\
\hline \multicolumn{3}{|l|}{ Protein synthesis } \\
\hline$\alpha$-1,3-Mannosyl-glycoprotein 2- $\beta$ - $N$-acetylglucosaminyltransferase & Mgat1 & 0.75 \\
\hline$\beta$ GICNAc $\beta$ 1,3-galactosyltransferase, polypeptide 4 & B3galt4 & 1.37 \\
\hline Coilin & Coil & 1.51 \\
\hline Hairy/enhancer-of-split related with YRPW motif-like (predicted) & Heyl_predicted & 1.24 \\
\hline Protease (prosome, macropain) 28 subunit, $\alpha$ & Psme1 & 0.83 \\
\hline Thyrotropin releasing hormone receptor & Trhr & 1.29 \\
\hline UDP-glucose ceramide glucosyltransferase & Ugcg & 1.26 \\
\hline \multicolumn{3}{|l|}{ Channel } \\
\hline Potassium channel subunit (Slack) & $R G D: 621106$ & 1.51 \\
\hline Potassium channel, subfamily K, member 10 & Kenk10 & 1.32 \\
\hline Potassium voltage-gated channel, subfamily H (eag-related), member 1 & Kenh1 & 1.27 \\
\hline Solute carrier family 25 (mitochondrial carrier, Aralar), member 12 (predicted) & Slc25a12_predicted & 0.70 \\
\hline Solute carrier family 41 , member 2 (predicted) & Slc41a2_predicted & 1.43 \\
\hline Solute carrier family 6 (neurotransmitter transporter, L-proline), member 7 & Slc6a7 & 0.74 \\
\hline Solute carrier organic anion transporter family, member 1a4 & Slcola4 & 0.81 \\
\hline Transient receptor potential cation channel, subfamily C, member 4 & Trpc4 & 1.37 \\
\hline \multicolumn{3}{|l|}{ Cytoskeleton } \\
\hline Actinin $\alpha 4$ & Actn4 & 0.78 \\
\hline Radixin & $R G D: 1359472$ & 0.74 \\
\hline Rapostlin & Fnbp1 & 0.68 \\
\hline RIKEN CDNA B130055L09 (predicted) similar to & RGD1309236_predicted & 0.77 \\
\hline Tubulin $\alpha-8$ chain ( $\alpha$-tubulin 8 ), similar to & LOC500377 & 1.36 \\
\hline Tubulin tyrosine ligase & Ttl & 1.44 \\
\hline Vimentin & $\operatorname{Vim}$ & 0.67 \\
\hline WAS protein family, member 2 (predicted) & Wasf2 & 0.80 \\
\hline \multicolumn{3}{|l|}{ Inflammation } \\
\hline B-cell CLL/lymphoma 7C (predicted) & Bcl7c_predicted & 1.29 \\
\hline CD74 antigen (invariant polpypeptide of major histocompatibility class II antigen-ass.) & $C d 74$ & 0.61 \\
\hline Chemokine (C-C motif) receptor 6 (predicted) & Ccr6 & 0.72 \\
\hline Chemokine (C-X-C motif) receptor 4 & Cxcr4 & 0.64 \\
\hline Chemokine-like factor super family 6 (predicted) & Cklfsf6 & 0.71 \\
\hline GATA binding protein 2 & Gata2 & 1.25 \\
\hline Interferon-induced protein with tetratricopeptide repeats 2 (predicted) & Ifit2_predicted & 0.73 \\
\hline Interleukin 12a & II12a & 1.35 \\
\hline Leukocyte receptor cluster (LRC) member 8 (predicted) & Leng8_predicted & 1.49 \\
\hline Scavenger receptor class B, member 1 & Scarb1 & 0.83 \\
\hline Tumor necrosis factor (ligand) superfamily, member 13 (predicted) & Tnfsf13_predicted & 0.76 \\
\hline \multicolumn{3}{|l|}{ Metabolism } \\
\hline 3-Hydroxy-3-methylglutaryl-coenzyme A reductase & Hmgcr & 1.20 \\
\hline Acetoacetyl-CoA synthetase & Aacs & 1.32 \\
\hline Angiotensin II receptor-associated protein & $R G D: 1359346$ & 0.80 \\
\hline$\beta$-Galactoside $\alpha 2,6$ sialyltransferase 2 & St6gal2 & 0.73 \\
\hline Cytochrome P450, family 4, subfamily a, polypeptide 14 & Cур4a14 & 1.63 \\
\hline Hexokinase 2 & $H k 2$ & 0.77 \\
\hline Microsomal glutathione S-transferase 2 (predicted) & Mgst2_predicted & 1.37 \\
\hline Pyruvate dehydrogenase kinase, isoenzyme 3 & Pdk3 & 1.33 \\
\hline Retinoic acid receptor responder (tazarotene induced) 2 (predicted) & Rarres2 & 1.37 \\
\hline \multicolumn{3}{|l|}{ Mitochondrial } \\
\hline Aconitase 2, mitochondrial & Aco2 & 0.52 \\
\hline Carbonic anhydrase VB, mitochondrial & Ca5b & 1.2 \\
\hline Mitochondrial protein, $18 \mathrm{kDa}$ & $R G D: 1359705$ & 0.81 \\
\hline Mitochondrial ribosomal protein L16 & Mrpl16 & 0.67 \\
\hline Mitochondrial ribosomal protein L40 & Mrpl40 & 1.21 \\
\hline \multicolumn{3}{|l|}{ Protease } \\
\hline Carboxypeptidase A2 (pancreatic) (predicted) & Cpa2_predicted & 0.64 \\
\hline Carboxypeptidase D & $C p d$ & 0.64 \\
\hline 0-Sialoglycoprotein endopeptidase (predicted) & Osgep_predicted & 0.76 \\
\hline Proteasome (prosome, macropain) subunit, $\beta$ type 10 (predicted) & Psmb10_predicted & 1.33 \\
\hline Proteosome (prosome, macropain) subunit, $\beta$ type 9 & Psmb9 & 0.73 \\
\hline \multicolumn{3}{|l|}{ Transport } \\
\hline ATP-binding cassette, subfamily C (CFTR/MRP), member 5 & Abcc5 & 1.23 \\
\hline Zinc finger protein 292 & Znf292 & 0.82 \\
\hline \multicolumn{3}{|l|}{ Apoptosis/stress } \\
\hline LOC500348 similar to apoptosis facilitator & Bcl-2-like protein 14 & 1.43 \\
\hline Tripartite motif protein 47 (predicted) & Trim47_predicted & $\begin{array}{c}1.32 \\
\text { (Table continues.) }\end{array}$ \\
\hline
\end{tabular}


Table 2. Continued

\begin{tabular}{|c|c|c|}
\hline Description & Gene symbol & Fold change \\
\hline \multicolumn{3}{|l|}{ Heat shock protein } \\
\hline Heat shock protein 2 & Hspa2 & 0.73 \\
\hline \multicolumn{3}{|l|}{ Guidance } \\
\hline Sema domain, transmembrane domain (TM), and cytoplasmic domain, (semaphorin) 6A (predicted) & Sema6a_predicted & 0.74 \\
\hline Unc-5 homolog C (C. elegans) & Unc5c & 0.70 \\
\hline \multicolumn{3}{|l|}{ Adhesion } \\
\hline 5'-Nucleotidase, cytosolic II-like 1 (predicted) & Col10a1 & 0.68 \\
\hline Cell adhesion molecule nectin- $3 \gamma$, similar to & LOC363780 & 1.28 \\
\hline Fibulin 1 (predicted) & Fbln1_predicted & 0.63 \\
\hline Glycoprotein (transmembrane) nmb & Gpnmb & 0.77 \\
\hline High mobility group protein 1 (HMG-1) (Amphoterin) similar to & Hmgb1 & 0.79 \\
\hline LRRC36 homolog (human) & Lrrc36 & 1.89 \\
\hline Matrix metallopeptidase 3 & Mmp3 & 1.32 \\
\hline Neurotrimin; hypothetical gene supported by NM_017354 & Hnt; LOC360435 & 0.74 \\
\hline Procollagen, type XI, $\alpha 1$ & Col11a1 & 0.70 \\
\hline Procollagen, type XXVII, $\alpha 1$ & Col27a1 & 0.79 \\
\hline Proteoglycan peptide core protein & $\begin{array}{l}\text { RGD: } 619969 \\
\text { Protocadtherin 7, similar }\end{array}$ & 0.79 \\
\hline Protocadherin 7 isoform c precursor; brain-heart [Homo sapiens] similar to & to & 0.83 \\
\hline Reelin & Reln & 0.77 \\
\hline Sialic acid binding lg-like lectin 10 (predicted) & Siglec10_predicted & 2.82 \\
\hline Syndecan 2 & Sdc2 & 0.81 \\
\hline Tissue inhibitor of metalloproteinase 2 & Timp2 & 0.80 \\
\hline Transmembrane 4 superfamily member 1 (predicted) & Tm4sf1_predicted & 0.70 \\
\hline Transmembrane 4 superfamily member 11 & Tm4sf11 & 0.76 \\
\hline Transmembrane 4 superfamily member 7 (predicted) & Tm4sf7_predicted & 0.75 \\
\hline Transmembrane protein vezatin & RGD:1359117 & 1.45 \\
\hline \multicolumn{3}{|l|}{ Synapse formation/maintenance } \\
\hline Adrenergic receptor, $\alpha$ 2c & Adra2c & 1.34 \\
\hline Bardet-Biedl syndrome 4 (predicted) & Bbs4_predicted & 0.82 \\
\hline Calsyntenin 2 & Clstn2 & 1.23 \\
\hline Catechol-0-methyltransferase & Comt & 1.37 \\
\hline Discs, large homolog 2 (Drosophila) & Dlgh2 & 1.38 \\
\hline Erythrocyte protein band 4.1-like 4b (predicted) & Epb4.114b_predicted & 0.74 \\
\hline Homer homolog 3 (Drosophila) & Homer3 & 1.57 \\
\hline Latrophilin 2 & Lphn2 & 0.81 \\
\hline Lin-7 homolog a (C. elegans) & Lin7a & 0.79 \\
\hline Membrane-bound $\mathrm{C} 2$ domain containing protein & $M b c 2$ & 1.50 \\
\hline Neuregulin 1 & Nrg1 & 1.25 \\
\hline Piccolo (presynaptic cytomatrix protein) & Pclo & 1.38 \\
\hline Synapsin III & Syn3 & 0.82 \\
\hline \multicolumn{3}{|l|}{ Growth } \\
\hline Brain-derived neurotrophic factor & Bdnf & 0.64 \\
\hline Glial cell line-derived neurotrophic factor family receptor $\alpha 1$ & Gfra1 & 1.30 \\
\hline Hepatoma-derived growth factor, related protein 2 & Hdgfrp2 & 0.76 \\
\hline Neurotrophic tyrosine kinase, receptor, type 1 & Ntrk1 & 1.30 \\
\hline Phosphatidylcholine transfer protein & Pctp & 1.24 \\
\hline Transforming growth factor, $\beta 2$ & Tgfb2 & 0.74 \\
\hline Transforming growth factor, $\beta$ induced & Tgfbi & 0.79 \\
\hline
\end{tabular}

Shown are differentially regulated genes (1 week after injury, denervated side after forced limb use in comparison with forced nonuse) belonging to the categories of signaling, transcription, protein synthesis, channel, cytoskeleton inflammation, metabolism, mitochondrial, protease, transport, apoptosis, stress, heat shock protein, guidance, adhesion, synapse formation, and growth that show fold changes of $\geq 1.2$ or $\leq 0.8$ (upregulated genes are in bold).

were forced to train their impaired side, but this increase did not reach significance $(p>0.05)$, probably because of the relatively small contribution of midline-crossing CST fibers to excitatory input in the intermediate zone (Fig. $8 D-H)$.

Gene expression differences in the denervated ventral horn of animals forced to use their impaired limb and animals that could not use their impaired limb

To identify genes within the denervated cervical gray matter that might play a role in activity-dependent growth, arborization, and synapse formation, we used gene chip arrays on sham-operated as well as lesioned animals either forced to rely on their impaired or unimpaired limb for 1 week. The ventral gray matter of the denervated side was dissected and used for analysis (Fig. 9A, B).

Comparison of lesioned with sham-operated animals showed injury-induced expression of specific sets of genes in the denervated gray matter. After injury, 441 genes were differently regulated in animals that could not use their impaired limb and 872 genes were regulated in injured animals that relied on their impaired forelimb (fold change, $\geq 1.2$ or $\leq 0.8$ ). Injury led to the upregulation of inflammation-related molecules, ion channels, and transporters, as well as the regulation of growth factors, guidance molecules, extracellular matrix (ECM) molecules, and mol- 
ecules involved in synapse formation as shown in previous studies (Bareyre and Schwab, 2003). A table of all regulated genes in response to injury is provided in the supplemental material (available at www.jneurosci.org).

Microarrays of sham-operated animals showed 311 differentially expressed transcripts (fold change, $\geq 1.2$ or $\leq 0.8$ ) within the used compared with the nonused denervated side of which 223 were coding for known proteins. A large proportion $(37.9 \%)$ of these differentially regulated genes were associated with cytoskeletal functions $(4.9 \%)$, neurite growth $(0.4 \%)$ and guidance $(0.9 \%)$, cell adhesion and ECM $(7.1 \%)$, synaptic function $(0.9 \%)$, signaling (13.4\%), and transcription (10.3\%) (Fig. 9C, Table 1). Analysis of microarrays in lesioned animals revealed similar numbers; 337 genes coding for 249 known proteins were differently regulated (fold change, $\geq 1.2$ or $\leq 0.8$ ) within the used compared with the nonused denervated gray matter (Fig. 9C, Table 2 ). Interestingly, the proportion of genes related to growth (2.8\%), synapse formation (5.2\%), and adhesion $(8.0 \%)$ was much higher in lesioned than in sham-operated animals after forced limb use (Fig. 9C).

\section{Discussion}

The present study shows that growth and synapse formation of CST fibers from the intact side into the denervated spinal cord after unilateral CST injury is enhanced by forced use of the impaired limb. Forced limb use led to the upregulation of mRNAs involved in neuronal outgrowth, cytoskeletal rearrangements, adhesion and guidance, as well as synapse formation in the denervated cervical gray matter. Growth and arborization of CST fibers was accompanied by marked behavioral improvements, which led to full restoration of skilled forepaw movements in the horizontal ladder test, whereas animals that could not use their impaired limb remained permanently and severely impaired.

\section{Forced limb use leads to functional recovery}

Interruption of CST input to the cervical spinal cord resulted in a permanent impairment of skilled forelimb function as shown in previous studies (Whishaw et al., 1993; Piecharka et al., 2005). The same result was obtained in injured rats with immobilized impaired forelimbs. The cast allowed minor movements of the restricted forelimb, which may have helped to prevent muscle atrophy and allowed some degree of spontaneous behavioral improvements as shown in sham-operated animals. Nevertheless, an impaired forelimb might be more susceptible to cast restriction than the intact forelimb of a sham-operated animal, and the poor recovery of forelimb function might be attributable to some degree of muscle atrophy. Interestingly, we did not observe a difference between control animals without a cast that were therefore able to voluntarily use their impaired forelimb and animals that were actively prevented from using their limb. This might be explained by an increased reliance on the intact forelimb and paw, a phenomenon known as "learned disuse" in freely moving animals (Kartje-Tillotson and Castro, 1980; Jones and Schallert, 1992) and stroke patients (Taub et al., 1999). In sharp contrast, full recovery of forelimb function after pyramidotomy was observed by 3 weeks of forced limb use. This is in line with previous studies in which forced use of the impaired forelimb led to behavioral recovery in animal models of stroke (Nudo et al., 1996; Bland et al., 2001) as well as in stroke patients (CIMT) (Taub et al., 1999). The cast forced animals to completely rely on their impaired side for everyday behavior, thereby training a broad range of movements. Forced limb use might, therefore, lead to improvements in a variety of locomotor movements in contrast to other training paradigms in which training of one specific task came at the cost of a nontrained task (De Leon et al., 1998; Girgis et al., 2007). Forced use immediately after injury did not lead to locomotor deficits or increased tissue damage as seen after cortical lesion (Humm et al., 1998). In our model, we injured descending fibers at the medullary level, which left cell bodies undamaged and possibly less vulnerable to elevated glutamate levels in response to training (Kozlowski et al., 1996; Humm et al., 1999). To show behavioral recovery immediately after injury and training, we tested our animals on the horizontal ladder. The horizontal ladder test requires precise movements of forelimb and digits and is a sensitive test to study forelimb recovery after CST injury (Metz and Whishaw, 2002; Starkey et al., 2005; Bolton et al., 2006). Although the pellet reaching test allows a very detailed analysis of various movement components after pyramidotomy (Whishaw et al., 1993; Thallmair et al., 1998), it would have required some time for retraining (Z'Graggen et al., 1998).

\section{Forced limb use enhances CST plasticity}

Unilateral pyramidotomy induced growth of axons from the intact CST into the contralateral, denervated gray matter where fibers arborized and established glutamatergic synapses. We were able to demonstrate CST outgrowth by colocalization of midlinecrossing fibers with the growth cone marker $2 \mathrm{G} 13$ as early as 1 week after injury. 2G13 exclusively labels growing axons (Stettler et al., 1999) and provides a valuable alternative to GAP-43 which also stains nongrowing fibers (Curtis et al., 1993; Kapfhammer and Schwab, 1994).

Three weeks after injury and forced limb use, the number of labeled axons within the denervated gray matter was significantly increased compared with animals that could not use their impaired limb. Although fiber density was also high in nonconstrained animals, functional reinnervation was increased only in animals that had to rely on their impaired limb as shown by the significantly higher number of BDA-labeled boutons as well as a slight but not significant increase in the total density of vGlut1positive structures indicating that physical activity might lead to significant changes especially at the synaptic and connectivity level.

The increased fiber density is probably reflecting local sprouting of new, as well as preexisting fibers. Camera lucida reconstructions also clearly demonstrated a contribution of ipsilateral ventral projections in accordance with previous studies (Weidner et al., 2001; Brus-Ramer et al., 2007). Sprouting of midline-crossing as well as ipsilateral fibers occurs spontaneously in response to CST lesion; however, it is enhanced by interventions that increase CNS fiber growth and plasticity (Thallmair et al., 1998; Zhou et al., 2003). In injured animals, CST fibers also grew toward deeper laminas of the ventral and the dorsal horn, thereby resembling the pattern of normal CST innervation. A remarkable finding was the preference of midline-crossing fibers for the ventral part of the gray matter, which has been observed in previous studies (Raineteau et al., 2002; BrusRamer et al., 2007). It suggests a higher growth potential of motor CST fibers and/or the presence of local signals that support targetdirected growth of axon collaterals toward ventral, motor circuits. Candidates for such signals were indeed found in our Affymetrix Chip analysis (see below). Although we cannot completely exclude the possibility that the higher density of labeling in the denervated spinal cord is attributable to an increased BDA transport into preexisting small diameter collaterals, the total number of BDA-labeled axons in the CST was equal in all treatment groups, and there is no evidence so far for changes in tracer transport in an intact tract in response to physical activity. 


\section{CST and functional recovery}

Improvements of forepaw placement on the horizontal ladder in response to forced limb use were seen as early as 1 week after injury, whereas changes in axonal growth and branching were only detected at a later stage. This suggests that forced limb use has a beneficial influence on motor performance by involving a variety of intraspinal and supraspinal systems (Hess and Donoghue, 1994; Wolpaw, 1997; Tillakaratne et al., 2000). Intraspinal changes might contribute to behavioral improvements observed within the first week after injury, whereas structural reorganization probably requires a certain amount of time after the onset of training to be detected as suggested by Kleim et al. (2004).

Because of its accessibility and defined morphology, we demonstrate morphological changes in response to injury and forced limb use in the intact CST, but it is clear that structural plasticity of other descending tracts may also contribute to the behavioral recovery. Rubrospinal and corticospinal tracts can compensate for each other to a certain extent after injury (Martin and Ghez, 1988; Raineteau et al., 2002). The reticulospinal system is left intact in our lesion paradigm and might also contribute to the training effect. Nevertheless, control of precision movements, in particular of hand/forepaw, is a major function of the motor CST (Castro, 1972; Kalil and Schneider, 1975), and the contribution of uninjured CST fibers on behavioral improvements has been shown in previous studies (Kartje-Tillotson et al., 1987; Thallmair et al., 1998).

\section{Intraspinal changes induced by CST denervation and forelimb training}

Complete transection of one CST and forced limb use led to increased growth/stabilization of midline-crossing CST fibers, suggesting a mechanism of competition for synaptic space and trophic support as previously described after pyramidotomy and/or electrical stimulation of the intact CST (Martin et al., 2004; Brus-Ramer et al., 2007). Interestingly, electrical stimulation leads to increased outgrowth of ventral CST fibers in intact animals, whereas forced limb use alone was not sufficient to induce structural rearrangements.

Pyramidotomy was shown to induce the expression of specific sets of genes in the denervated gray matter of the spinal cord (Bareyre et al., 2002; Bareyre and Schwab, 2003). These results are in line with our present observations. The effect of training on gene expression in the cervical spinal cord is still poorly understood. Forced limb reduces growth-inhibitory factors and extracellular matrix molecules and regulated growth-promoting factors and cytoskeletal dynamics. There was regulation of adhesion molecules, axonal guidance molecules, and components of synapse formation [e.g., glial cell linederived neurotrophic factor receptor $\alpha 1$ (Gfra1), brain-derived neurotrophic factor (Bdnf), as well as Neuregulin1 (Nlgn1) and Piccolo $(P c l)$ ] (Garcès et al., 2000; Phelps et al., 2002; Liu et al., 2005; Tao-Cheng, 2006; Fischbach, 2007). Because of the variability in lesion models, training paradigms, investigated time points, or spinal levels, there is no agreement about the importance or specificity of different factors. BDNF for example plays an important role in synapse formation and stabilization (Poo, 2001) and physical exercise in intact and spinal cord-injured animals increases mRNA levels of BDNF (Cotman and Berchtold, 2002; Gómez-Pinilla et al., 2002; Ying et al., 2005). Training after cervical lesion, however, did not increase BDNF levels (Girgis et al., 2007), and 1 week after lesion and forced limb use we even observed a decrease within the denervated gray matter.

Our study clearly shows that rehabilitative forelimb training regulates compensatory plastic changes at the spinal level after injury followed by behavioral recovery. The analysis of the specificity and importance of individual molecules involved in activity-dependent reorganization will be an exciting task for future studies.

\section{References}

Adams JC (1992) Biotin amplification of biotin and horseradish peroxidase signals in histochemical stains. J Histochem Cytochem 40:1457-1463.

Barbeau H, Rossignol S (1994) Enhancement of locomotor recovery following spinal cord injury. Curr Opin Neurol 7:517-524.

Bareyre FM, Schwab ME (2003) Inflammation, degeneration and regeneration in the injured spinal cord: insights from DNA microarrays. Trends Neurosci 26:555-563.

Bareyre FM, Haudenschild B, Schwab ME (2002) Long-lasting sprouting and gene expression changes induced by the monoclonal antibody IN-1 in the adult spinal cord. J Neurosci 22:7097-7110.

Bareyre FM, Kerschensteiner M, Raineteau O, Mettenleiter TC, Weinmann O, Schwab ME (2004) The injured spinal cord spontaneously forms a new intraspinal circuit in adult rats. Nat Neurosci 7:269-277.

Bland ST, Pillai RN, Aronowski J, Grotta JC, Schallert T (2001) Early overuse and disuse of the affected forelimb after moderately severe intraluminal suture occlusion of the middle cerebral artery in rats. Behav Brain Res 126:33-41.

Blight AR (1993) Remyelination, revascularization, and recovery of function in experimental spinal cord injury. Adv Neurol 59:91-104.

Bolton DA, Tse AD, Ballermann M, Misiaszek JE, Fouad K (2006) Task specific adaptations in rat locomotion: runway versus horizontal ladder. Behav Brain Res 168:272-279.

Brösamle C, Schwab ME (2000) Ipsilateral, ventral corticospinal tract of the adult rat: ultrastructure, myelination and synaptic connections. J Neurocytol 29:499-507.

Brown LT Jr (1971) Projections and termination of the corticospinal tract in rodents. Exp Brain Res 13:432-450.

Brus-Ramer M, Carmel JB, Chakrabarty S, Martin JH (2007) Electrical stimulation of spared corticospinal axons augments connections with ipsilateral spinal motor circuits after injury. J Neurosci 27:13793-13801.

Burns SP, Golding DG, Rolle WA Jr, Graziani V, Ditunno JF Jr (1997) Recovery of ambulation in motor-incomplete tetraplegia. Arch Phys Med Rehabil 78:1169-1172.

Cafferty WB, Strittmatter SM (2006) The Nogo-Nogo receptor pathway limits a spectrum of adult CNS axonal growth. J Neurosci 26:12242-12250.

Castro AJ (1972) Motor performance in rats. The effects of pyramidal tract section. Brain Res 44:313-323.

Cotman CW, Berchtold NC (2002) Exercise: a behavioral intervention to enhance brain health and plasticity. Trends Neurosci 25:295-301.

Curtis R, Averill S, Priestley JV, Wilkin GP (1993) The distribution of GAP-43 in normal rat spinal cord. J Neurocytol 22:39-50.

De Leon RD, Hodgson JA, Roy RR, Edgerton VR (1998) Full weight-bearing hindlimb standing following stand training in the adult spinal cat. J Neurophysiol 80:83-91.

Dietz V, Wirz M, Curt A, Colombo G (1998) Locomotor pattern in paraplegic patients: training effects and recovery of spinal cord function. Spinal Cord 36:380-390.

Dobkin BH (2000) Spinal and supraspinal plasticity after incomplete spinal cord injury: correlations between functional magnetic resonance imaging and engaged locomotor networks. Prog Brain Res 128:99-111.

Edgerton VR, Tillakaratne NJ, Bigbee AJ, de Leon RD, Roy RR (2004) Plasticity of the spinal neural circuitry after injury. Annu Rev Neurosci 27:145-167.

Fischbach GD (2007) NRG1 and synaptic function in the CNS. Neuron 54:495-497.

Garcès A, Haase G, Airaksinen MS, Livet J, Filippi P, deLapeyrière O (2000) GFR $\alpha 1$ is required for development of distinct subpopulations of motoneuron. J Neurosci 20:4992-5000.

Girgis J, Merrett D, Kirkland S, Metz GA, Verge V, Fouad K (2007) Reaching training in rats with spinal cord injury promotes plasticity and task specific recovery. Brain 130:2993-3003.

Gómez-Pinilla F, Ying Z, Roy RR, Molteni R, Edgerton VR (2002) Voluntary exercise induces a BDNF-mediated mechanism that promotes neuroplasticity. J Neurophysiol 88:2187-2195.

Herzog A, Brösamle C (1997) 'Semifree-floating' treatment: a simple and fast method to process consecutive sections for immunohistochemistry and neuronal tracing. J Neurosci Methods 72:57-63.

Hess G, Donoghue JP (1994) Long-term potentiation of horizontal connec- 
tions provides a mechanism to reorganize cortical motor maps. J Neurophysiol 71:2543-2547.

Humm JL, Kozlowski DA, James DC, Gotts JE, Schallert T (1998) Usedependent exacerbation of brain damage occurs during an early postlesion vulnerable period. Brain Res 783:286-292.

Humm JL, Kozlowski DA, Bland ST, James DC, Schallert T (1999) Usedependent exaggeration of brain injury: is glutamate involved? Exp Neurol 157:349-358.

Jones TA, Schallert T (1992) Overgrowth and pruning of dendrites in adult rats recovering from neocortical damage. Brain Res 581:156-160.

Jones TA, Schallert T (1994) Use-dependent growth of pyramidal neurons after neocortical damage. J Neurosci 14:2140-2152.

Joosten EA, Schuitman RL, Vermelis ME, Dederen PJ (1992) Postnatal development of the ipsilateral corticospinal component in rat spinal cord: a light and electron microscopic anterograde HRP study. J Comp Neurol 326:133-146.

Kalil K, Schneider GE (1975) Motor performance following unilateral pyramidal tract lesions in the hamster. Brain Res 100:170-174.

Kapfhammer JP, Schwab ME (1994) Inverse patterns of myelination and GAP-43 expression in the adult CNS: neurite growth inhibitors as regulators of neuronal plasticity? J Comp Neurol 340:194-206.

Kartje-Tillotson G, Castro AJ (1980) Limb preference after unilateral pyramidotomy in adult and neonatal rats. Physiol Behav 24:293-296.

Kartje-Tillotson G, O’Donoghue DL, Dauzvardis MF, Castro AJ (1987) Pyramidotomy abolishes the abnormal movements evoked by intracortical microstimulation in adult rats that sustained neonatal cortical lesions. Brain Res 415:172-177.

Kleim JA, Hogg TM, VandenBerg PM, Cooper NR, Bruneau R, Remple M (2004) Cortical synaptogenesis and motor map reorganization occur during late, but not early, phase of motor skill learning. J Neurosci 24:628-633.

Kozlowski DA, James DC, Schallert T (1996) Use-dependent exaggeration of neuronal injury after unilateral sensorimotor cortex lesions. J Neurosci 16:4776-4786.

Little JW, Ditunno JF Jr, Stiens SA, Harris RM (1999) Incomplete spinal cord injury: neuronal mechanisms of motor recovery and hyperreflexia. Arch Phys Med Rehabil 80:587-599.

Liu Y, Ford BD, Mann MA, Fischbach GD (2005) Neuregulin-1 increases the proliferation of neuronal progenitors from embryonic neural stem cells. Dev Biol 283:437-445.

Martin JH, Ghez C (1988) Red nucleus and motor cortex: parallel motor systems for the initiation and control of skilled movement. Behav Brain Res 28:217-223.

Martin JH, Choy M, Pullman S, Meng Z (2004) Corticospinal system development depends on motor experience. J Neurosci 24:2122-2132.

McKenna JE, Prusky GT, Whishaw IQ (2000) Cervical motoneuron topography reflects the proximodistal organization of muscles and movements of the rat forelimb: a retrograde carbocyanine dye analysis. J Comp Neurol 419:286-296.

Metz GA, Whishaw IQ (2002) Cortical and subcortical lesions impair skilled walking in the ladder rung walking test: a new task to evaluate foreand hindlimb stepping, placing, and co-ordination. J Neurosci Methods 115:169-179.

Müllner A, Gonzenbach RR, Weinmann O, Schnell L, Liebscher T, Schwab ME (2008) Lamina-specific restoration of serotonergic projections after Nogo-A antibody treatment of spinal cord injury in rats. Eur J Neurosci 27:326-333.

Neafsey EJ, Bold EL, Haas G, Hurley-Gius KM, Quirk G, Sievert CF, Terreberry RR (1986) The organization of the rat motor cortex: a microstimulation mapping study. Brain Res 396:77-96.

Nudo RJ, Masterton RB (1988) Descending pathways to the spinal cord: a comparative study of 22 mammals. J Comp Neurol 277:53-79.

Nudo RJ, Masterton RB (1990) Descending pathways to the spinal cord, III: Sites of origin of the corticospinal tract. J Comp Neurol 296:559-583.

Nudo RJ, Wise BM, SiFuentes F, Milliken GW (1996) Neural substrates for the effects of rehabilitative training on motor recovery after ischemic infarct. Science 272:1791-1794.

Persson S, Boulland JL, Aspling M, Larsson M, Fremeau RT Jr, Edwards RH, Storm-Mathisen J, Chaudhry FA, Broman J (2006) Distribution of vesicular glutamate transporters 1 and 2 in the rat spinal cord, with a note on the spinocervical tract. J Comp Neurol 497:683-701.
Phelps PE, Rich R, Dupuy-Davies S, Ríos Y, Wong T (2002) Evidence for a cell-specific action of Reelin in the spinal cord. Dev Biol 244:180-198.

Piecharka DM, Kleim JA, Whishaw IQ (2005) Limits on recovery in the corticospinal tract of the rat: partial lesions impair skilled reaching and the topographic representation of the forelimb in motor cortex. Brain Res Bull 66:203-211.

Poo MM (2001) Neurotrophins as synaptic modulators. Nat Rev Neurosci 2:24-32.

Raineteau O, Schwab ME (2001) Plasticity of motor systems after incomplete spinal cord injury. Nat Rev Neurosci 2:263-273.

Raineteau O, Fouad K, Bareyre FM, Schwab ME (2002) Reorganization of descending motor tracts in the rat spinal cord. Eur J Neurosci 16:1761-1771.

Rossignol S, Drew T, Brustein E, Jiang W (1999) Locomotor performance and adaptation after partial or complete spinal cord lesions in the cat. Prog Brain Res 123:349-365.

Schallert T, Kozlowski DA, Humm JL, Cocke RR (1997) Use-dependent structural events in recovery of function. Adv Neurol 73:229-238.

Schreyer DJ, Jones EG (1982) Growth and target finding by axons of the corticospinal tract in prenatal and postnatal rats. Neuroscience 7:1837-1853.

Schwab ME (2002) Repairing the injured spinal cord. Science 295:10291031.

Schwab ME (2004) Nogo and axon regeneration. Curr Opin Neurobiol 14:118-124.

Starkey ML, Barritt AW, Yip PK, Davies M, Hamers FP, McMahon SB, Bradbury EJ (2005) Assessing behavioural function following a pyramidotomy lesion of the corticospinal tract in adult mice. Exp Neurol 195:524-539.

Stettler O, Bush MS, Kasper M, Schlosshauer B, Gordon-Weeks PR (1999) Monoclonal antibody 2G13, a new axonal growth cone marker. J Neurocytol 28:1035-1044.

Tao-Cheng JH (2006) Activity-related redistribution of presynaptic proteins at the active zone. Neuroscience 141:1217-1224.

Taub E, Uswatte G, Pidikiti R (1999) Constraint-induced movement therapy: a new family of techniques with broad application to physical rehabilitation-a clinical review. J Rehabil Res Dev 36:237-251.

Thallmair M, Metz GA, Z'Graggen WJ, Raineteau O, Kartje GL, Schwab ME (1998) Neurite growth inhibitors restrict plasticity and functional recovery following corticospinal tract lesions. Nat Neurosci 1:124-131.

Tillakaratne NJ, Mouria M, Ziv NB, Roy RR, Edgerton VR, Tobin AJ (2000) Increased expression of glutamate decarboxylase $(\operatorname{GAD}(67))$ in feline lumbar spinal cord after complete thoracic spinal cord transection. J Neurosci Res 60:219-230.

Vahlsing HL, Feringa ER (1980) A ventral uncrossed corticospinal tract in the rat. Exp Neurol 70:282-287.

Varoqui H, Schäfer MK, Zhu H, Weihe E, Erickson JD (2002) Identification of the differentiation-associated $\mathrm{Na}^{+} / \mathrm{PI}$ transporter as a novel vesicular glutamate transporter expressed in a distinct set of glutamatergic synapses. J Neurosci 22:142-155.

Weidner N, Ner A, Salimi N, Tuszynski MH (2001) Spontaneous corticospinal axonal plasticity and functional recovery after adult central nervous system injury. Proc Natl Acad Sci U S A 98:3513-3518.

Whishaw IQ, Pellis SM, Gorny B, Kolb B, Tetzlaff W (1993) Proximal and distal impairments in rat forelimb use in reaching follow unilateral pyramidal tract lesions. Behav Brain Res 56:59-76.

Wolpaw JR (1997) The complex structure of a simple memory. Trends Neurosci 20:588-594.

Ying Z, Roy RR, Edgerton VR, Gómez-Pinilla F (2005) Exercise restores levels of neurotrophins and synaptic plasticity following spinal cord injury. Exp Neurol 193:411-419.

Yiu G, He Z (2006) Glial inhibition of CNS axon regeneration. Nat Rev Neurosci 7:617-627.

Z'Graggen WJ, Metz GA, Kartje GL, Thallmair M, Schwab ME (1998) Functional recovery and enhanced corticofugal plasticity after unilateral pyramidal tract lesion and blockade of myelin-associated neurite growth inhibitors in adult rats. J Neurosci 18:4744-4757.

Zhou L, Shine HD (2003) Neurotrophic factors expressed in both cortex and spinal cord induce axonal plasticity after spinal cord injury. J Neurosci Res 74:221-226.

Zhou L, Baumgartner BJ, Hill-Felberg SJ, McGowen LR, Shine HD (2003) Neurotrophin-3 expressed in situ induces axonal plasticity in the adult injured spinal cord. J Neurosci 23:1424-1431. 